\title{
Compound A, a Selective Glucocorticoid Receptor Modulator, Enhances Heat Shock Protein Hsp70 Gene Promoter Activation
}

\author{
Ilse M. Beck ${ }^{1,2 *}$, Zuzanna J. Drebert ${ }^{1}$, Ruben Hoya-Arias ${ }^{2 \times a, a c}$, Ali A. Bahar ${ }^{2 \times b}$, Michael Devos ${ }^{5}$, \\ Dorien Clarisse ${ }^{1,3,4}$, Sofie Desmet ${ }^{3,4}$, Nadia Bougarne ${ }^{3,4}$, Bart Ruttens ${ }^{7,8}$, Valerie Gossye ${ }^{2 x d}$, \\ Geertrui Denecker ${ }^{5}$, Sam Lievens ${ }^{3,4}$, Marc Bracke ${ }^{1}$, Jan Tavernier ${ }^{3,4}$, Wim Declercq ${ }^{5}$, Kris Gevaert ${ }^{7,8}$, Wim \\ Vanden Berghe ${ }^{2,6}$, Guy Haegeman ${ }^{2 x e}$, Karolien De Bosscher ${ }^{2,3,4}$
}

1 Laboratory of Experimental Cancer Research (LECR), Department of Radiation Therapy \& Experimental Cancer Research, Ghent University, Ghent, Belgium, 2 Human Oncology \& Pathogenesis Program, Memorial Sloan-Kettering Cancer Center, New York, New York, United States of America, 3 Cytokine Receptor Lab, Department of Medical Protein Research, VIB, Ghent, Belgium, 4 Cytokine Receptor Lab, Department of Biochemistry, Ghent University, Ghent, Belgium, 5 Molecular Signaling and Cell Death Unit, VIB Department for Molecular Biomedical Research, Ghent University, Ghent (Zwijnaarde), Belgium, 6 Lab Protein Chemistry, Proteomics \& Epigenetic Signaling (PPES), Department Biomedical Sciences, University of Antwerp, Wilrijk, Belgium, 7 Department of Medical Protein Research, VIB, Ghent, Belgium, 8 Department of Biochemistry, Ghent University, Ghent, Belgium

\begin{abstract}
Compound A possesses glucocorticoid receptor (GR)-dependent anti-inflammatory properties. Just like classical GR ligands, Compound A can repress NF- $\kappa B$-mediated gene expression. However, the monomeric Compound A-activated GR is unable to trigger glucocorticoid response element-regulated gene expression. The heat shock response potently activates heat shock factor 1 (HSF1), upregulates Hsp70, a known GR chaperone, and also modulates various aspects of inflammation. We found that the selective GR modulator Compound A and heat shock trigger similar cellular effects in A549 lung epithelial cells. With regard to their anti-inflammatory mechanism, heat shock and Compound $A$ are both able to reduce TNFstimulated $\mathrm{I} \kappa \mathrm{B} \alpha$ degradation and NF- $\kappa \mathrm{B}$ p65 nuclear translocation. We established an interaction between Compound Aactivated GR and Hsp70, but remarkably, although the presence of the Hsp70 chaperone as such appears pivotal for the Compound A-mediated inflammatory gene repression, subsequent novel Hsp70 protein synthesis is uncoupled from an observed CpdA-induced Hsp70 mRNA upregulation and hence obsolete in mediating CpdA's anti-inflammatory effect. The lack of a Compound A-induced increase in Hsp70 protein levels in A549 cells is not mediated by a rapid proteasomal degradation of Hsp70 or by a Compound A-induced general block on translation. Similar to heat shock, Compound A can upregulate transcription of Hsp70 genes in various cell lines and BALB/c mice. Interestingly, whereas Compound Adependent Hsp70 promoter activation is GR-dependent but HSF1-independent, heat shock-induced Hsp70 expression alternatively occurs in a GR-independent and HSF1-dependent manner in A549 lung epithelial cells.
\end{abstract}

Citation: Beck IM, Drebert ZJ, Hoya-Arias R, Bahar AA, Devos M, et al. (2013) Compound A, a Selective Glucocorticoid Receptor Modulator, Enhances Heat Shock Protein Hsp70 Gene Promoter Activation. PLoS ONE 8(7): e69115. doi:10.1371/journal.pone.0069115

Editor: Michael Sherman, Boston University Medical School, United States of America

Received November 16, 2012; Accepted June 6, 2013; Published July 30, 2013

Copyright: (C) 2013 Beck et al. This is an open-access article distributed under the terms of the Creative Commons Attribution License, which permits unrestricted use, distribution, and reproduction in any medium, provided the original author and source are credited.

Funding: IMB (full) and KDB (in part) are postdoctoral fellows supported by the Research Foundation-Flanders (FWO) (www.fwo.be). SD holds a Ph. D. fellowship of the Research Foundation-Flanders (FWO) (www.fwo.be). DC is supported by the Flemish League against Cancer 'Vlaamse Liga tegen Kanker' (VLK) (www. tegenkanker.be) and thus the research project was realized with the support of the VLK. NB is sponsored by a Strategic Basic Research (SBO) project of IWTVlaanderen (www.iwt.be). Financial support was provided by 'Geconcerteerde Onderzoeksactiviteiten' (GOA) from UGent (www.ugent.be) and by Interuniversity Attraction Poles (IAP) [6/18] (http://www.belspo.be/belspo/iap/index_en.stm). The funders had no role in study design, data collection and analysis, decision to publish, or preparation of the manuscript.

Competing Interests: The authors have declared that no competing interests exist.

*E-mail: Ilse.Beck@Ugent.be

aa Current address: Molecular Pharmacology and Chemistry Program, Sloan-Kettering Institute, Memorial Sloan-Kettering Cancer Center, New York, New York, United States of America

ab Current address: Department of Biomedical and Chemical Engineering, Syracuse University, Syracuse, New York, United States of America

ac Current address: Syracuse Biomaterials Institute, Syracuse University Syracuse, New York, United States of America

ad Current address: Amgen NV, Brussels, Belgium

ae Current address: Division of Molecular Medicine, Department of Research and Development, Faculty of Medicine, Siriraj hospital, Mahidol University, Bangkok, Thailand

\section{Introduction}

Inflammation is a complex immune response of tissues to harmful stimuli, such as the self-produced tumor necrosis factor (TNF) characterized by an activator protein-1 (AP-1) and/or nuclear factor $\kappa \mathrm{B}(\mathrm{NF}-\mathrm{\kappa B})$-mediated generation of cytokines and chemokines, e.g. IL6 and IL8. In unstimulated cells, NF- $\kappa \mathrm{B}$ is restrained in the cytoplasm by the NF- $\mathrm{BB}$-binding inhibitory protein I $\kappa$ B. Upon induction, the I $\kappa \mathrm{B}$ kinase (IKK) complex, comprising two catalytic components, IKK $\alpha$ and $\operatorname{IKK} \beta$, and a regulatory component IKK $\gamma$ (NEMO), can phosphorylate IкB, destining this inhibitory factor for ubiquitination and subsequent 
degradation by the $26 \mathrm{~S}$ proteasome. Ensuing, the freed and activated NF- $\mathrm{BB}$ p65-p50 heterodimer translocates into the nucleus, where it will bind onto specific promoter recognition sites and activate multiple pro-inflammatory genes [1].

Glucocorticoids (GCs), the steroidal ligands of the glucocorticoid receptor (GR, NR3C1), are efficaciously used as antiinflammatory drugs. Structurally, the GR comprises a N-terminal domain in which a transactivation function is encoded, a DNAbinding domain which also functions in GR dimerization, and a C-terminal ligand-binding domain which harbors a second transactivation function [2]. The unactivated GR resides predominantly in the cytoplasm where a chaperone complex consisting of heat shock protein 70 (Hsp70), Hsp90 and variable immunophilins keeps the receptor in a ligand-receptive state [3]. After GCs bind to the GR, the receptor's conformation changes and as a result GR sheds its chaperone complex and translocates into the nucleus, where it can activate or repress specific gene transcription [2]. The GC-activated GR can positively affect gene expression via dimerized GR binding onto specific GC-responsive elements (GREs) in the promoter. Conversely, GC-activated GR can negatively interfere with gene expression via diverse mechanisms among which the binding of GR to a negative GRE, tethering of monomer GR to transcription factors such as NF- $\mathrm{KB}$, and the alteration of the composition of the transcription-initiating enhanceosome [2]. However, long-term therapy with GCs is burdened with a detrimental side-effect profile [4] driving ongoing research to develop new therapeutic strategies to combat inflammation. With this aim, we investigate Compound A (CpdA), a phenyl aziridine precursor molecule established as a selective GR modulator. CpdA is able to alter GR's conformation and drives it into the nucleus [5]. However, unlike classical GGs [6], CpdA does not stimulate GR Ser $^{211}$ phosphorylation [5] or GR dimerization [7]. Hence, CpdA-modulated GR does not transactivate GRE-regulated gene expression and safeguards the system from various classic GC-associated side effects [5]. This selective $\mathrm{GR}$ modulator is, however, a potent repressor of NF- $\kappa \mathrm{B}$-driven pro-inflammatory gene expression, both in vitro and in vivo [8]. Mechanistically, CpdA-activated GR diminishes the TNF-stimulated NF- $\kappa \mathrm{B}$ transactivation capacity and DNA binding [5]. As most GC therapy-associated side effects are linked to GR transactivation mechanisms [9], a selective GR modulator possibly holds great promise in future therapeutics combating inflammation.

Various stressors, including heat and proteotoxic stress, instigate the heat shock response $[10,11]$. This reaction functions to protect the cell and is characterized by the activation of the transcription factor heat shock factor 1 (HSF1) followed by the elevated gene expression of inducible heat shock proteins (Hsps), such as Hsp70 [11]. The heat shock-activated mechanism to stimulate Hsp70 promoter activity occurs via the activation of the transcription factor HSF1. In a resting state, HSFl is distributed throughout the cell as a monomer. Upon activation, HSF1 becomes hyperphosphorylated, trimerizes and aggregates in nuclear stress granules $[12,13]$. The activated HSF1 oligomers can bind onto a specific heat shock response element (HSE) to activate gene transcription of various inducible Hsps [14,15].

Physiologically, Hsp70 can play a role as a chaperoning molecule, ensuring proper folding and refolding of various proteins. As such, Hsp70 contributes to keep the unactivated GR in a ligand-receptive state [3]. The presence of Hsp70 has also been shown to be crucial for mice to resist TNF-induced lethality [16]. Moreover, elevated intracellular Hsp70 and activated HSF1 have been described to have anti-inflammatory abilities via disruption of the IKK complex, abrogation of I $\kappa \mathrm{B} \alpha$ degradation

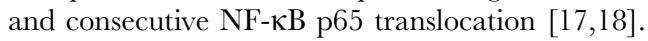

In brief, we report here on the modulation of $\mathrm{Hsp} 70$ promoter activity via different stimuli. Interestingly, the SGRM CpdA upregulates Hsp70 mRNA via a GR-dependent and HSF1independent mechanism. Although, CpdA, similar to heat shock, hampers TNF-stimulated $\mathrm{I} \kappa \mathrm{B} \alpha$ degradation and NF- $\kappa \mathrm{B}$ p65 nuclear translocation, its anti-inflammatory mechanism does not seem to require absolute de novo protein synthesis. Nonetheless, the presence of adequate levels of the Hsp70 chaperone is

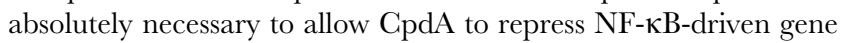
expression.

\section{Materials and Methods}

\section{Cell Culture \& Reagents}

A549 adenocarcinoma human alveolar basal epithelial cells were a kind gift from Dr. Ian Adcock [19]. PC-3 prostate adenocarcinoma cells were a kind gift from Dr. Schalken and Dr. Giroldi (Nijmegen, The Netherlands) [20]. HEK293T cells (ATCG ${ }^{\circledR}$ CRL-11268 ${ }^{\mathrm{TM}}$ ), L929sA murine fibrosarcoma cells [21] and other cells were cultured in DMEM with 10\% fetal calf serum, $100 \mathrm{U} / \mathrm{ml}$ penicillin and $0.1 \mathrm{mg} / \mathrm{ml}$ streptomycin. All cell lines were grown at $37^{\circ} \mathrm{C}$ under $5 \% \mathrm{CO}_{2}$.

Recombinant $\mathrm{TNF} \alpha$ production and purification to $99 \%$ homogeneity has been described previously [22]. Dexamethasone (DEX) and cycloheximide (CHX) were obtained from SigmaAldrich. CpdA was produced and stored as described [5]. TNF $\alpha$ was used at a final concentration of $2000 \mathrm{IU} / \mathrm{ml}$ and dissolved in medium. DEX and CpdA were dissolved in ethanol and used, respectively, at a $1 \mu \mathrm{M}$ and $10 \mu \mathrm{M}$ final concentration, unless stated otherwise in the figure legend. Cycloheximide (CHX) was dissolved in DMSO and used in a final concentration of $20 \mu \mathrm{g} / \mathrm{ml}$.

\section{Animals and Ethics Statement}

$\mathrm{BALB} / \mathrm{c}$ mice were obtained from Charles River. The animal experiment was performed in accordance with all Belgian legal and ethical requirements and approved by the local ethics committee of Ghent University (Permit number: 07-012). In order to minimize suffering, intraperitoneal injections were performed with $26 \mathrm{G}$ needles and mice were sacrificed by cervical dislocation under Ketamin/Xylazin anaesthesia.

\section{Plasmids}

The plasmid $\mathrm{p}(\mathrm{IL} 6 \kappa \mathrm{B})_{3} 50$ hu.IL6P-luc+ and $\mathrm{p}(\mathrm{GRE})_{2} 50$ hu.IL6P-luc+ were described previously $[23,24]$. The $\mathrm{p}(\mathrm{GRE})_{2} 50-$ hu.IL6P-luc+ plasmid was derived from the $\mathrm{p}(\mathrm{IL} 6 \kappa \mathrm{B})_{3} 50$ hu.IL6Pluc+ by replacing the $\kappa \mathrm{B}$ motifs with two consensus GRE sites. The heat-inducible mHsp70i-luc reporter gene construct was kindly donated to us by Dr. H Moo Kwon (Baltimore, Maryland) [25].

\section{Bait, prey and Reporter Constructs}

All constructs used in this report were generated by standard PCR- or restriction based cloning procedures. The pCLG-GR plasmid was generated by amplifying the human GR-coding sequence of a hGR-containing expression plasmid using primers GGGGAGCTCGGACTCGAAAGAATCATTAAC and GGGGCGGCGGCTCACTTTTGATGAAACAGAA, cutting the amplicon with SacI and NotI restriction enzymes and ligating the resulting fragment into SacI-NotI digested pCLG backbone [26]. The pMG1 plasmid encoding an unfused gp130 receptor fragment as an empty prey control was obtained by opening the pMG1 vector [27] using EcoRI and XhoI, blunting the vector 
backbone through Pfu DNA Polymerase and self-ligation. The prey plasmids pMG1-HSP90AA1 and pMG1-HSP70 were created by Gateway transfer of the full size HSP90AAl and HSP70 ORFs, obtained as entry clones from the hORFeome collection [28] into the Gateway compatible pMGl prey destination vector as described earlier [29]. The pXP2d2-rPAP1luciferase reporter has been described elsewhere [30,31].

\section{Transfection \& Reporter Gene Assays}

Stable transfection of $\mathrm{mHsp} 70$ i-luc into L929sA cells was performed by the calcium phosphate precipitation protocol as described [23]. Transient transfections of $\mathrm{p}(\mathrm{IL} 6 \kappa \mathrm{kB})_{3} 50 \mathrm{hu}$.IL6Pluct or $\mathrm{p}(\mathrm{GRE})_{2} 50$ hu.IL6P-luc+ in A549 cells were performed via lipofectamine (Invitrogen)-based procedures, as described [32]. Post-inductions, cells were washed with PBS and lysed (TROPIX). Total solvent concentration was kept similar in all conditions. Reporter gene expression was corrected by normalization to the co-expressed $\beta$-galactosidase ( $\beta$-gal) protein levels, as assayed via a Galacto-Light kit (TROPIX).

For the MAPPIT analysis, HEK293T cells were cultured in a $8 \% \mathrm{CO}_{2}$ humidified atmosphere at $37^{\circ} \mathrm{C}$ and grown in DMEM with $10 \%$ fetal calf serum $\left(\right.$ Gibco $\left.^{\circledR}\right) .10000$ cells were seeded in black 96-well plates. One day later, the cells were transiently cotransfected with either a DHFR-bait plasmid (irrelevant bait, as a negative control) or a GR $\alpha$-bait plasmid, together with the STAT3-responsive rPAP1-luci reporter plasmid and the desired prey-plasmid. The empty prey was used as a negative control. Twenty-four hours after transfection cells were stimulated with leptin $(100 \mathrm{ng} / \mathrm{ml})$ or leptin in combination with DEX $(1 \mu \mathrm{M})$ or CpdA $(10 \mu \mathrm{M})$ for another $24 \mathrm{~h}$ or were left untreated (NS). All inductions were performed at least in triplicate. Total cell lysates were assayed for promoter activity of the relative reporter genes via a luciferase assay, performed according to manufacturer's instructions (Promega). Luciferase activity was measured by chemiluminescence in a TopCount NXT luminometer (Perkin Elmer).

\section{RT-(q)PCR}

For inductions, total solvent concentration was kept similar in all conditions. Total RNA was isolated using TRIzol Reagent (Life Technologies). cDNA was generated with minimally 500ng of total RNA, using oligo-d(T) primers and MMLV RT enzyme (Promega) and amplified with Taq polymerase (Promega) and sequence-specific primers targeted at HSPA1A, HPSA1B, or GAPDH PCR products, generated under non-saturating conditions. The products were separated by PAGE and were detected by ethidium bromide staining and subsequently visualized using UV. To quantify the bands obtained via RT-PCR, we applied ImageJ software based analysis (http://rsb.info.nih.gov/ij/). The area under curve (AUC) of the specific signal was corrected for the AUC of the housekeeping gene control.

Female 8 week old BALB/c mice were subjected to the indicated treatment and total RNA was purified out of total skin grafts using RNeasy+ kit (Qiagen). RNA was transcribed to cDNA with iScript cDNA synthesis kit (Bio-Rad). RT-qPCR analysis of animal and cellular samples was performed using the Lightcycler 480 system and Lightcycler qPCR reagents (Roche), to assay specific GR, HSPA1A, HSPA1B, IL8, GAPDH, $\beta$-actin, cyclophilin, 36B4, 28S, RPL13a, HMBS, ACTB mRNA levels. qPCR was performed in triplicate. All primer sequences are available upon request. Specific signal was normalized to housekeeping control.

\section{Protein Analyses \& Antibodies}

For Western analysis, total cell lysates were prepared using SDS sample buffer (50mM Tris pH6.8; 2\% SDS; 10\% glycerol; bromophenol blue, 100mM DTT) or TOTEX buffer $(20 \mathrm{mM}$ Hepes/KOH pH 7.9; 0.35 M NaCl; 20\% glycerol; $1 \%$ NP40; $1 \mathrm{mM} \mathrm{MgCl2}$; 0.5 mM EDTA; $0.1 \mathrm{mM}$ EGTA; 2mM pefabloc; $10 \mu \mathrm{g} / \mathrm{ml}$ aprotinin; $5 \mathrm{mM}$ DTT) followed by standard Western blotting and antibody probing procedures (Santa Cruz Biotechnology). Samples prepared with SDS sample buffer are loaded at an equal volume of maximally $30 \mu \mathrm{l}$ and equal loading is assayed via a loading control. Samples prepared with TOTEX buffer are analysed for protein concentration via a Bradford analysis [33] and maximally $40 \mu \mathrm{g}$ is loaded for Western blot analysis.

The antibodies (Abs), used in the Western blot analyses, were

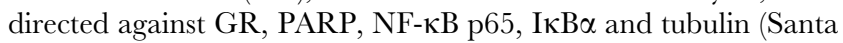
Cruz Biotechnology), $\beta$-catenin (Sigma-Aldrich) and phosphorylated S6 ribosomal protein (Cell Signalling Technology). Antibodies directed against inducible Hsp70 were purchased via different companies, but it was verified that all recognize inducible Hsp70: anti-Hsp72 SPA-810 monoclonal Ab (Stressgen) and anti-Hsp70 polyconal Ab(Santa Cruz Biotechnologies; sc-1060). All primary antibodies were used at 1/1000 dilutions; except anti-tubulin, which was used at $1 / 2000$. The secondary antibodies were used with the following dilutions: anti-Mouse IgG-HRP (NA931V, GEHealthcare UK Limited) at 1/3000, anti-Rabbit IgG-HRP (NA935V, GE-Healthcare UK Limited) at 1/4000, anti-Rat IgG-HRP (NA934V, GE-Healthcare UK Limited) at 1/1000, and anti-goat IgG-HRP (sc-2020, Santa Cruz Biotechnologies) also at $1 / 1000$.

To quantify the bands obtained via Western blot analysis, we applied band densitometric analysis via Image J software (http:// rsb.info.nih.gov/ij/). The area under curve (AUC) of the specific signal was corrected for the AUC of the loading control. The value for the 'Solv' condition was set as 1 and other conditions were recalculated correspondingly to allow ratio comparisons. For the Hsp70 cell lysate ELISA, we used the EKS-700B Hsp70 ELISA kit according to the manufacturer's instructions (Stressgen).

\section{LC-MS/MS Analysis}

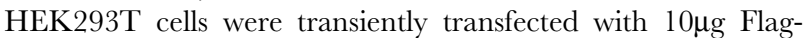
tagged GR using the calcium phosphate transfection method. 24 hours after transfection and after induction with solvent or Compound A $(10 \mu \mathrm{M})$ for $3 \mathrm{~h}$, cells were lysed either in $1 \mathrm{ml} \mathrm{NP40}$ non-denaturing buffer (50 mM Tris. $\mathrm{HCl}$ pH 7.5; $125 \mathrm{mM} \mathrm{NaCl}$; $5 \%$ glycerol; $0.2 \% \quad \mathrm{NP} 40 ; 1.5 \mathrm{mM} \quad \mathrm{MgCl}_{2}$; and cOmplete ${ }^{\circledR}$ protease inhibitor cocktail (1 tablet/50ml buffer)) or $1 \mathrm{ml}$ Buffer A $(10 \mathrm{mM}$ Hepes pH $7.5 ; 10 \mathrm{mM} \mathrm{KCl} ; 1.5 \mathrm{mM} \mathrm{MgCl} 2 ; 0.1 \%$ NP40; 0.5mM DTT; and for cOmplete ${ }^{\circledR}$ protease inhibitor cocktail cocktail (1 tablet/50ml buffer)). Input controls $(50 \mu \mathrm{l} / \mathrm{sample})$ of either buffer were kept aside for control western blot analyses. Flag-tagged GR was immunoprecipitated with $40 \mu \mathrm{l}$ Flag beads overnight. Cell lysates in NP40 non-denaturing buffer were processed as follows: after 5 washes with $5 \mathrm{mM}$ TEAB (triethylammonium bicarbonate) buffer, elution was performed with $600 \mu \mathrm{l}$ of $100 \mu \mathrm{g} / \mathrm{ml}$ Flag peptide in $5 \mathrm{mM}$ TEAB buffer. Cell lysates in buffer A were processed as follows: after 5 washes with $\mathrm{NH}_{4} \mathrm{HCO}_{3}(50 \mathrm{mM} \mathrm{pH}$ 8), elution was done with $450 \mu \mathrm{l}$ ammoniumhydroxide $\left(\mathrm{NH}_{4} \mathrm{OH}\right)(1 \%)$.

Reagents and solvents were purchased from Sigma-Aldrich (St. Louis, MO, USA), except acetonitrile (Baker, Center Valley, PA, USA) and formic acid (Biosolve, Valkenswaard, The Netherlands), and used without further purification, unless specified. $\mathrm{H}_{2} \mathrm{O}$ for (HPLC) buffers was produced with a Millipore (Billerica, MA, USA) RIOs-DI water purification system, coupled with the MilliQ 
Table 1. Overview of identified heat shock proteins via LC-MS/MS.

\begin{tabular}{|c|c|c|}
\hline Identified proteins & Number of spectra & Run \\
\hline Heat shock $70 \mathrm{kDa}$ protein 1A/1B (HSP71_HUMAN) & 99 & CpdA (FLAG) \\
\hline Heat shock $70 \mathrm{kDa}$ protein 1A/1B (HSP71_HUMAN) & 48 & $\mathrm{CpdA}\left(\mathrm{NH}_{4} \mathrm{OH}\right)$ \\
\hline Heat shock $70 \mathrm{kDa}$ protein 1A/1B (HSP71_HUMAN) & 52 & $\mathrm{NI}(\mathrm{FLAG})$ \\
\hline Heat shock $70 \mathrm{kDa}$ protein 1A/1B (HSP71_HUMAN) & 50 & $\mathrm{NI}\left(\mathrm{NH}_{4} \mathrm{OH}\right)$ \\
\hline Heat shock cognate $71 \mathrm{kDa}$ protein (HSP7C_HUMAN) & 45 & CpdA (FLAG) \\
\hline Heat shock cognate $71 \mathrm{kDa}$ protein (HSP7C_HUMAN) & 45 & $\mathrm{CpdA}\left(\mathrm{NH}_{4} \mathrm{OH}\right)$ \\
\hline Heat shock cognate $71 \mathrm{kDa}$ protein (HSP7C_HUMAN) & 43 & $\mathrm{NI}(\mathrm{FLAG})$ \\
\hline Heat shock cognate $71 \mathrm{kDa}$ protein (HSP7C_HUMAN) & 37 & $\mathrm{NI}\left(\mathrm{NH}_{4} \mathrm{OH}\right)$ \\
\hline Heat shock protein HSP 90-alpha (HS90A_HUMAN) & 1 & CpdA (FLAG) \\
\hline Heat shock protein HSP 90-alpha (HS90A_HUMAN) & 1 & $\mathrm{CpdA}\left(\mathrm{NH}_{4} \mathrm{OH}\right)$ \\
\hline Heat shock protein HSP 90-beta (HS90B_HUMAN) & 8 & CpdA (FLAG) \\
\hline Heat shock protein HSP 90-beta (HS90B_HUMAN) & 7 & $\mathrm{NI}(\mathrm{FLAG})$ \\
\hline Heat shock protein HSP 90-beta (HS90B_HUMAN) & 3 & $\mathrm{NI}\left(\mathrm{NH}_{4} \mathrm{OH}\right)$ \\
\hline
\end{tabular}

HEK293T cells were transfected with Flag-hGR $\alpha$ via calcium phosphate and following stimulation with either solvent ( $\mathrm{NI})$ or $10 \mu \mathrm{M}$ CpdA (CpdA), immunoprecipitated using Flag beads (plasmid and methodology described in [7]. Two identical set-ups were done in parallel, yet, using two different elution methods, via $\mathrm{NH}_{4} \mathrm{OH}$, as indicated, or via the Flag peptide (FLAG, $100 \mu \mathrm{g} / \mathrm{ml}$ ). The Swiss-Prot accession is indicated in the protein description field. Per protein, the number of identified MS/MS spectra (at $99 \%$ confidence settings (Mascot)) is indicated.

doi:10.1371/journal.pone.0069115.t001

Reference $\mathrm{A}^{+}$system equipped with a $22 \mu \mathrm{m}$ filter and a C18 column to remove organic impurities.

Immunoprecipated samples were dried completely in a rotational vacuum concentrator (RVG 2-33 IR, Martin Christ, Osterode am Harz, Germany). The residue was reconstituted in $500 \mu \mathrm{l}$ of $50 \mathrm{mM}$ TEAB buffer $(\mathrm{pH} 8)$ and the resulting solution was heated at $95^{\circ} \mathrm{C}$ for $10 \mathrm{~min}$. After cooling on ice for at least $5 \mathrm{~min}$, trypsin $(2 \mu \mathrm{g}$, Sequencing Grade Modified Trypsin, Porcine, Promega, Leiden, The Netherlands) was added and the samples were overnight incubated at $37^{\circ} \mathrm{C}$. Samples were again dried completely in a rotational vacuum concentrator and reconstituted in $20 \mu \mathrm{l}$ of $2 \%$ acetonitrile in $0.1 \%$ TFA. Samples were centrifuged for 10 minutes at $15000 \mathrm{~g}$, and the supernatant was transferred to a vial for LC-MS/MS analysis.

The samples were analyzed on a LC-MS/MS system consisting of an Ultimate 3000 RSLG nano (Dionex, Amsterdam, The Netherlands) in-line connected to a LTQ Orbitrap Velos (Thermo Fisher Scientific, Bremen, Germany). The sample was loaded on a trapping column (made in-house, $100 \mu \mathrm{m}$ internal diameter (I.D.) $\times 20 \mathrm{~mm}, 5 \mu \mathrm{m}$ beads C18 Reprosil-HD, Dr. Maisch). After back-flushing from the trapping column, the sample was loaded on a reverse-phase column (made in-house, $75 \mu \mathrm{m} \mathrm{I.D} \times 150 \mathrm{~mm}$, $5 \mu \mathrm{m}$ beads C18 Reprosil-HD, Dr. Maisch) with solvent A $(0.1 \%$ trifluoroacetic acid, 2\% acetonitrile), and were separated with a linear gradient from $2 \%$ solvent $\mathrm{A}^{\prime}(0.1 \%$ formic acid) to $55 \%$ solvent B' $(0.1 \%$ formic acid and $80 \%$ acetonitrile) at a flow rate of $300 \mathrm{nl} / \mathrm{min}$ followed by a wash reaching $100 \%$ solvent B.

The mass spectrometer was operated in data-dependent mode, automatically switching between MS and MS/MS acquisition for the ten most abundant peaks in a given MS spectrum. Full scan MS spectra were acquired in the Orbitrap at a target value of 1E6 with a resolution of 60,000 . The ten most intense ions were then isolated for fragmentation in the linear ion trap, with a dynamic exclusion of $30 \mathrm{~s}$. Peptides were fragmented after filling the ion trap at a target value of $1 \mathrm{E} 4$ ion counts. The mass spectrometer's nanospray source was expanded with an Active Background Ion Reduction Device (Abird, ESI Source Solutions). From the MS/ MS data in each LC run, Mascot Generic Files were created using the Mascot Distiller software (version 2.4.3.3, Matrix Science, www.matrixscience.com/Distiller). While generating these peak lists, grouping of spectra was allowed in Distiller with a maximum intermediate retention time of $30 \mathrm{~s}$ and a maximum intermediate scan count of 5 was used where possible. Grouping was done with $0.005 \mathrm{~m} / \mathrm{z}$ precursor tolerance. A peak list was only generated when the MS/MS spectrum contained more than 10 peaks. There was no de-isotoping and the relative signal to noise limit was set at 2. These peak lists were then searched with the Mascot search engine (MatrixScience) using the Mascot Daemon interface (version 2.4.0, Matrix Science). Spectra were searched against the human subsection of the Swiss-Prot database (version 2013_01 of UniProtKB/Swiss-Prot protein database containing 20,232 human sequence entries). Variable modifications were set to methionine oxidation, pyro-glutamate formation of amino terminal glutamine, and acetylation of the $\mathrm{N}$-terminus and lysine side chains. The mass tolerance on precursor ions was set to $10 \mathrm{ppm}$ (with Mascot's C13 option set to 1), and on fragment ions to 0.5 $\mathrm{Da}$. The peptide charge was set to $1+, 2+, 3+$ and the instrument setting was put on ESI-TRAP. Enzyme was set to trypsin, allowing 1 missed cleavage, and cleavage was also allowed when arginine or lysine are followed by proline. Only peptides that were ranked one and scored above the threshold score, set at 99\% confidence, were withheld. All data management was done by ms_lims [34].

\section{siRNA Transfection}

A549 cells were seeded and the following day transiently transfected using the calcium phosphate precipitation technique as described before [35]. As indicated, cells were either transfected with siRNA control, siRNA GR (NR3Cl) or a combination of siRNA HSPA1A and HSPA1B (Dharmacon). Specific sequences and order numbers can be found in Table S1. Cells were incubated with the respective transfection mixtures overnight (16h). The following day, medium was replaced with DMEM, supplemented with $10 \%$ fetal calf serum, and cells were left to rest for $24 \mathrm{~h}$. Subsequent to the appropriate inductions, total RNA was isolated using TRIzol Reagent (Invitrogen, Life Technologies). To control for siRNA efficiencies, we collected control RNA samples 
A

Compound A

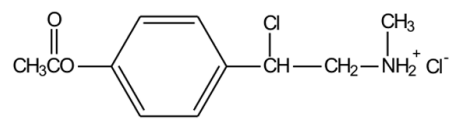

B

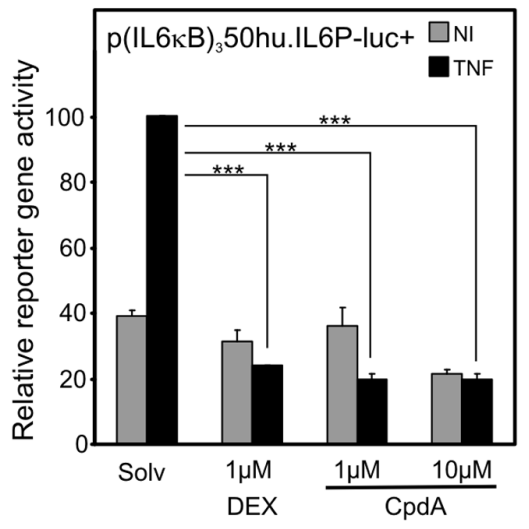

C

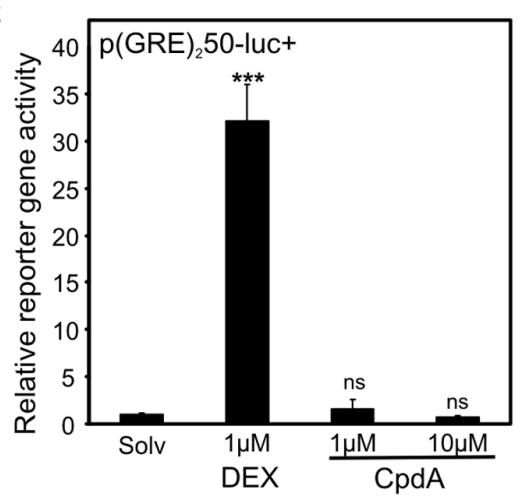

D

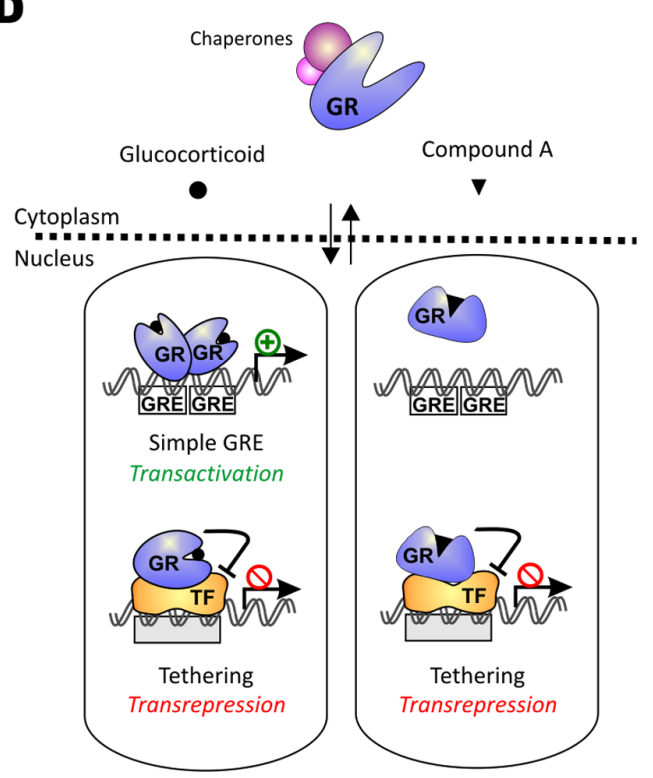

Figure 1. Compound $A$ is a selective GR modulator with NF-kB repressive capacity. (A) Compound A chemical structure (B) A549 cells, transiently transfected with $\mathrm{p}(\mathrm{IL} 6 \kappa \mathrm{B})_{3} 50$ hu.IL6P-luc+, were treated with solvent (Solv), DEX $(1 \mu \mathrm{M})$ or CpdA $(1 \mu \mathrm{M}$ or $10 \mu \mathrm{M})$ for $2 \mathrm{~h}$.
Subsequently, cells were induced with TNF $(2000 \mathrm{IU} / \mathrm{ml})$ for $6 \mathrm{~h}$ where indicated. $\beta$-gal control-corrected results were presented as relative reporter gene activity with the condition Solv/TNF set at 100 . Statistical analysis (ANOVA with Tukey's multiple comparison post test) was performed to show significant difference with the TNF condition for selected conditions (*** $p<0.001)$. (C) A549 cells, transiently transfected with $\mathrm{p}(\mathrm{GRE})_{2} 50$-luct, were treated with Solv, DEX $(1 \mu \mathrm{M})$ or CpdA $(1 \mu \mathrm{M}$ or $10 \mu \mathrm{M})$ for $8 \mathrm{~h}$. $\beta$-gal control-corrected results were presented as relative reporter gene activity with the condition Solv set at 1 . Statistical analysis (ANOVA with Tukey's multiple comparison post test) was performed to show significant difference with the Solv condition (ns not significant; ${ }^{* * *} \mathrm{p}<0.001$ ). Results are shown $+/-$ SD. Figures in $(B)$ and (C) are representative of at least 3 independent experiments. (D) Schematic model of gene modulatory GC and CpdA effects. While classic GCs can transactivate GRE-regulated genes and impede gene expression of specific target genes via a tethering transrepression mechanism (left panel), CpdA drives GR into a monomer formation that does not allow transcactivation of GRE-regulated gene expression. CpdA liganded GR can, however, still repress gene expression via transrepression (right panel).

doi:10.1371/journal.pone.0069115.g001

and total protein cell lysates (SDS Sample buffer) of control wells. RNA samples and control protein samples were analyzed, as described above.

\section{Immunofluorescence}

A549 cells, seeded on coverslips and incubated in Optimem (Gibco) for 48h, were induced as indicated. The protocol regarding fixation, permeabilization and staining was described [5]. Endogenous HSF1 or NF- $\kappa \mathrm{B}$ p65 was visualized using a specific Ab followed by Alexa Fluor 488 goat $\alpha$-rabbit IgG (Molecular Probes) secondary Ab. The antibodies directed against HSF1 and NF-кB p65 were purchased via Cell Signaling Technology and Santa Cruz, respectively. Cell nuclei were stained with DAPI $(0.4 \mu \mathrm{g} / \mathrm{ml})$. Alexa fluor 488 excitation or UVillumination via an Axiovert 200M immunofluorescence microscope (Zeiss) allowed recording of HSF1 or NF- $\mathrm{BB}$ p65, or DAPI signal, respectively, with a Zeiss Axiocam mMR. Images were processed using Axiovision Release 4.6.3-SP1 software.

Subcellular distribution of endogenous NF- $\kappa \mathrm{B}$ p65 was analyzed using Image J software integrated density analysis of cells in various images of the same sample. A representative image is shown. The distribution of $\mathrm{NF}-\kappa \mathrm{B}$ p65 in each cell is expressed as the percentage of nuclear NF- $\kappa \mathrm{B}$ p65 on a cell total of $100 \% \mathrm{NF}-\kappa \mathrm{B}$ p65 and total results of each experiment are presented as a scatter dot plot.

\section{Chromatin Immunoprecipitation (ChIP) Assay}

A549 cells were starved in 0\% DMEM for 48 hours. After treatments, cells were subjected to a ChIP assay against HSF1, as described [36]. ChIP analysis of endogenous HSF1 was performed with $\alpha$-HSF1 antibody (Cell Signaling Technology). Normal rabbit IgG (Santa Cruz) was used as a negative control in ChIP. The amount of sonicated protein:DNA complexes, present before immunoprecipitation (IP), is indicated by the input controls. Final DNA samples of bound immunoprecipitated and input fraction were purified via a QIAquick PGR purification kit (QIAGEN). Purified DNA samples, enriched with the immunoprecipitated protein, and input control DNA samples were subjected to qPCR in triplicate. Primer sequences are available upon request. Data obtained from immunoprecipitated samples were corrected for the signal of the respective input control and final integrated results were presented as 'Relative recruitment'. 
A

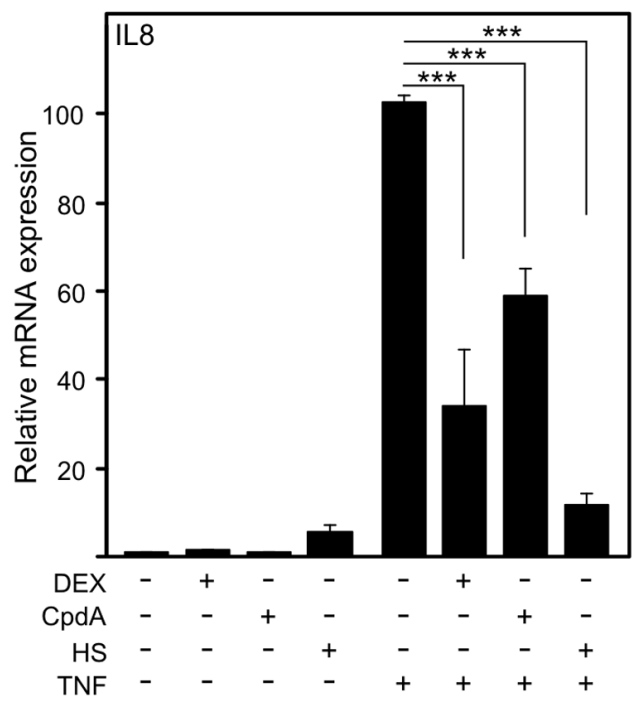

B

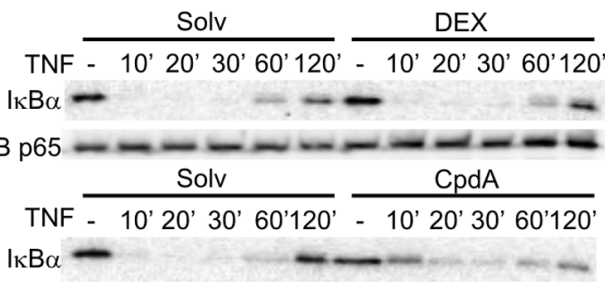

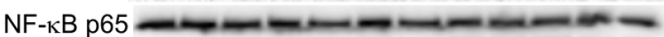

C

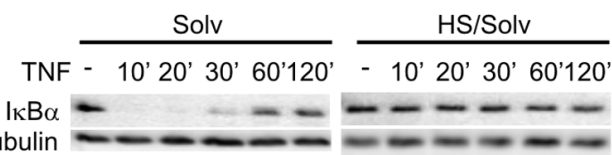

$\mathbf{E}$

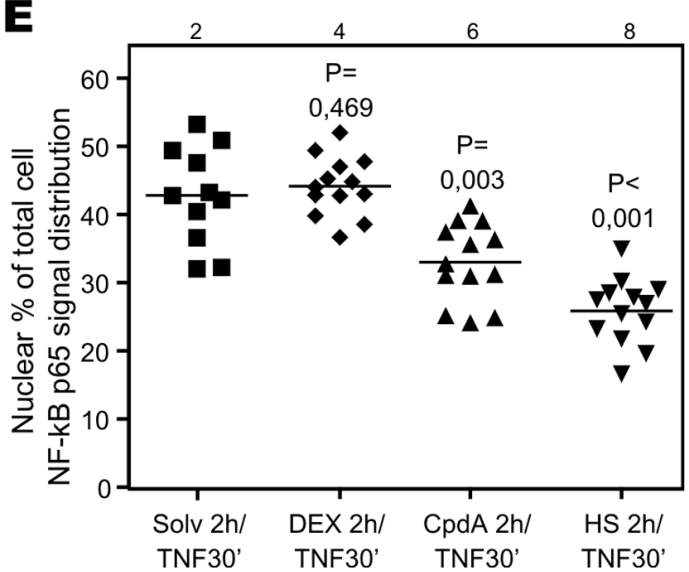

D

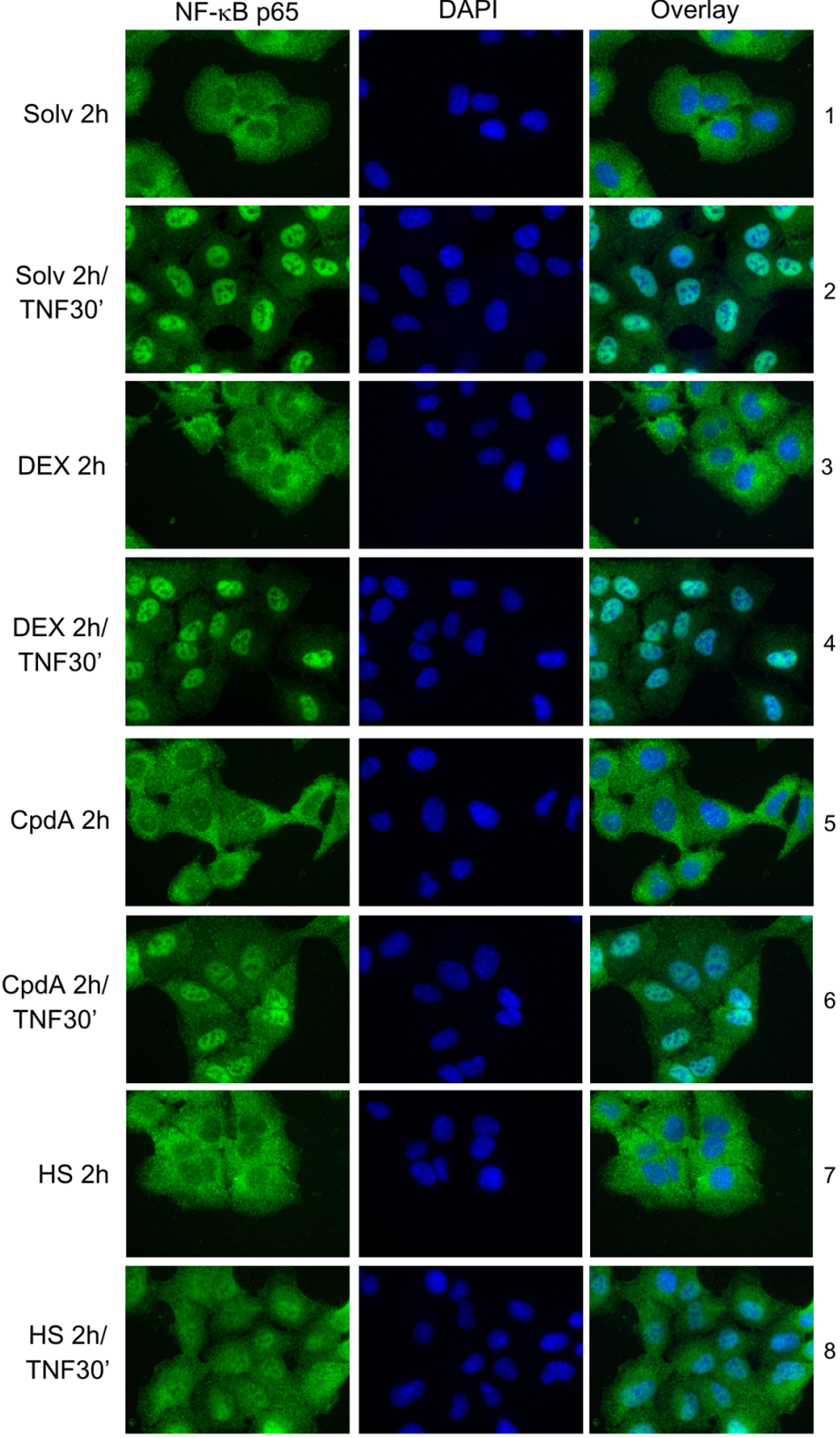

Figure 2. Both Compound $\mathbf{A}$ and heat shock diminish NF-kB-driven gene expression and NF-kB activation. (A) A549 cells, starved for $48 \mathrm{~h}$, were pretreated for $1.5 \mathrm{~h}$ with solvent (Solv), DEX $(1 \mu \mathrm{M}), \mathrm{CpdA}(10 \mu \mathrm{M})$ or subjected to heat shock treatment $\left(1 \mathrm{~h}\right.$ at $43^{\circ} \mathrm{C}$ and $30^{\prime}$ recovery at $\left.37^{\circ} \mathrm{C}\right)$, ensued with TNF (2000IU/ml) for 5.5h. Isolated total RNA was subjected to RT-qPCR assaying IL8 mRNA levels, normalized to cyclophilin household gene mRNA levels. The TNF condition was set at 100 and results were recalculated accordingly. These results are representative of 2 independent experiments. Statistical analysis (ANOVA and Tukey multiple comparison post test) were performed for selected pair-wise comparisons. (B) A549 cells, starved for $48 \mathrm{~h}$, were pretreated for $2 \mathrm{~h}$ with solvent (Solv), DEX (1 $\mu \mathrm{M})$ or CpdA $(10 \mu \mathrm{M})$, after which TNF(2000IU/ml) was added as indicated. Western blot analysis of total cells lysates detects $\mathrm{I} B \mathrm{~B} \alpha$ protein, with NF- $\kappa \mathrm{B}$ p 65 as loading control. This figure is representative for 2 independent experiments. (C) A549 cells, starved for $48 \mathrm{~h}$, were untreated or heat-shocked at $43^{\circ} \mathrm{C}$ for $2 \mathrm{~h}$. Ensuing, cells were treated by TNF (2000lU/ml) for the indicated times. Total cell lysates were analyzed as in (B), with tubulin as loading control. Results were obtained on 2 separate blots in one experiment. (D) A549 cells,

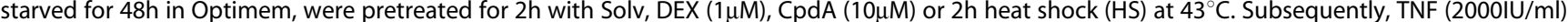
was added for 30', where indicated. After washing, fixation, and permeabilization, indirect immunofluorescence detects endogenous NF- $\mathrm{BB}$ p65. 
DAPI staining indicates the nuclei. Additionally, we present overlays. This figure is representative for 2 independent experiments. (E) ImageJ integrated density analysis of the TNF-treated conditions in (D) allows statistical analysis (Mann-Whitney $U$ test) and we show the P-value of comparisons to the Solv/TNF condition. These results are representative of 2 independent experiments. doi:10.1371/journal.pone.0069115.g002

\section{Statistical Analyses}

Statistical analyses were performed with a one-way analysis of variance (ANOVA) and Tukey's multiple comparison post test, an unpaired t-test or a non-parametric Mann-Whitney-U test, where appropriate, using the asymptotic significant P-values. Error bars indicate SD.

All materials and methods, as described in above are also valid for the figures S1, S2, S3, S4, S5, S6, S7, S8, S9, and S10 and tables $\mathrm{S} 1$ and $\mathrm{S} 2$. Additional materials en methods to understand figures S1, S2, S3, S4, S5, S6, S7, S8, S9, and S10 and tables S1 and $\mathrm{S} 2$ are added in support.

\section{Results}

\section{Compound A is a Selective GR Modulator with NF- $\mathrm{KB}$ Repressive Capacity}

To confirm the selective GR modulator status of CpdA (or 2-(4acetoxyphenyl)-2-chloro-N-methyl-ethylammonium chloride (Figure 1A) in A549 human epithelial cells, we performed reporter gene analyses with transiently transfected cells. The administration of the synthetic glucocorticoid dexamethasone (DEX) or CpdA to a TNF-stimulated NF- $\kappa \mathrm{B}$-driven promoter represses the reporter gene activity in a statistically significant manner (Figure 1B). Alternatively, whereas DEX can potently induce GRE-regulated promoter activity, CpdA has no significant effect on the reporter gene activity of $\mathrm{p}(\mathrm{GRE})_{2} 50$-luc+ (Figure 1G). Similar data were previously obtained in stably transfected L929sA cells [5]. To sum up, CpdA can be referred to as a selective GR modulator since it

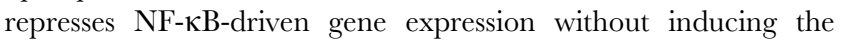
dimeric GR-mediated upregulation of GRE-regulated genes (Figure 1D)

\section{Both Compound A and Heat Shock Diminish NF-kB- driven Gene Expression and NF- $\kappa B$ Activation}

As it is described that heat shock or elevated Hsp70 can impede NF- $\kappa \mathrm{B}-$ mediated transcriptional activity via impairing $\mathrm{I} \kappa \mathrm{B} \alpha$ proteasomal degradation and limiting the subsequent NF- $\kappa \mathrm{B}$ p65 translocation $[18,37,38]$, we wondered whether the CpdAevoked repression of NF-kB-driven gene expression could be mediated by a similar mechanism. Hereto, we first established that all the stimuli we used, i.e. heat shock, CpdA and DEX are able to significantly inhibit TNF-stimulated NF- $\mathrm{BB}$-driven gene expression of IL8 (Figure 2A) and IL6 (Figure S1) in A549 cells. To explore potential mechanistic parallels, we first assayed whether CpdA could impede the TNF-stimulated IKK-mediated I $\mathrm{B} \alpha \alpha$ degradation in A549 cells. As expected, TNF addition prompted a complete degradation of $\mathrm{I} \kappa \mathrm{B} \alpha$, the level of which starts to rise again after $60^{\prime}$ of TNF treatment (Figure 2B-C). The GC DEX did not affect TNF-induced $\mathrm{I} \kappa \mathrm{B} \alpha$ degradation in A549 cells (Figure 2B), confirming our previous findings in L929sA cells [32]. In contrast, $\mathrm{CpdA}$ administration resulted in an incomplete I $\mathrm{B} \mathrm{B} \alpha$ degradation after TNF stimulation (Figure 2B). As expected from literature-based evidence in other cell systems, a heat shock treatment, leading to HSF1 activation and highly elevated Hsp70 protein levels, can indeed lead to a total block of the TNFstimulated proteasomal I $\kappa \mathrm{B} \alpha$ degradation (Figure $2 \mathrm{C}$ ). Because the I $\kappa \mathrm{B} \alpha-\mathrm{NF}-\kappa \mathrm{B}$ p 65 association controls the cytoplasmic localization

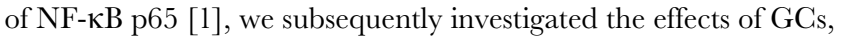
CpdA and heat shock on the TNF-stimulated NF-кB p65 nuclear translocation in A549 cells. We observed that 30' of TNF treatment triggers a subcellular shift of $\mathrm{NF}-\kappa \mathrm{B}$ p65 from the cytoplasm to the nucleus (Figure 2D, lanes 1vs2). Furthermore, we noticed that DEX does not affect the TNF-induced nuclear import of NF- $\kappa \mathrm{B}$ p65 (Figure 2D-E: lanes 2vs4). In contrast, pretreatment with CpdA slightly diminishes the TNF-stimulated NF-кB p65 translocation (Figure 2D-E: lanes 2vs6). Furthermore, pre-treatment with heat shock reduces the TNF-induced nuclear translocation of NF- $\kappa \mathrm{B}$ p65 in a significant manner (Figure 2D-E: lanes 2vs8). Cytoplasmic localization of NF- $\mathrm{BB}$ p65 in unstimulated cells was not altered by induction with DEX, CpdA or heat shock (Figure 2D: lanes 1vs3,5\&7). In line with these observations, CpdA hampers the TNF-induced I $\mathrm{B} \alpha$ degradation and/or NF- $\kappa \mathrm{B}$ p65 nuclear translocation also in fibroblast-like synovial (FLS) cells [39], primary microglial cells [40] and L929sA fibrosarcoma cells (Figure S2).

To summarize, CpdA reduces the TNF-stimulated I $\mathrm{KB} \alpha$ degradation and NF- $\kappa \mathrm{B}$ p65 translocation from the cytoplasm to the nucleus. Heat shock treatment totally abolishes TNFstimulated $\mathrm{I} \kappa \mathrm{B} \alpha$ degradation and reduces the TNF-induced nuclear translocation of NF- $\mathrm{BB} 65$, more profoundly. Correspond-

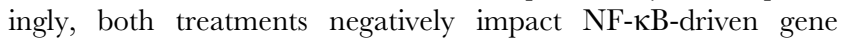
expression.

\section{Hsp70 is Required to Allow the anti-inflammatory Activity of Compound A}

To specifically address the possible role of Hsp70 in the CpdAmediated anti-inflammatory action mechanism, we knocked down Hsp70 in A549 cells via transfection of siRNA HSPA1A and siRNA HSPA1B, targeting Hsp70 mRNA. The distinct genes HSPA1A and HSPA1B, located in close proximity on chromosome 6 and displaying a 98\% sequence similarity, both code for Hsp70 protein. Tests to validate the efficacy of specific siRNA targeting Hsp70 in comparison to non-targeting siControl showed via $\mathrm{RT}$-qPCR that HSPA1A and HSPA1B mRNA levels were significantly knocked down (Figure 3A, left panel) and that, consequently, Hsp70 protein was nearly completely abolished (Figure 3A, right panel). Analysis of TNF-stimulated IL8 gene expression levels demonstrated, as expected, that CpdA can significantly inhibit IL8 gene transcription when cells were transfected with non-targeting siControl (Figure 3B: lanes 3vs4). However, when cellular Hsp70 levels were knocked down via transfection of Hsp70-targeting siRNA, CpdA completely failed to exert its anti-inflammatory effect on IL8 gene expression levels (Figure 3B: lanes 7vs8). Similar results were obtained for IL6 gene expression levels (Figure S3). In summary, adequate cellular levels of $\mathrm{Hsp} 70$ protein are required to allow CpdA-mediated repression of pro-inflammatory gene expression.

\section{Compound A Augments Hsp70 Gene Expression}

Since CpdA clearly shows parallels to heat shock with regard to its anti-inflammatory mechanism and since CpdA's anti-inflammatory mechanism relies on the presence of $\mathrm{Hsp} 70$, we studied the effect of CpdA on Hsp70 gene expression. First, we checked whether the selected primers could indeed detect heat shockinducible Hsp70 and whether the cell system is susceptible to heat shock-induced Hsp70 upregulation. Total RNA was isolated from A549 cells and resulting samples were subjected to RT-PCR for the detection of HSPAlA mRNA levels. Detection of GAPDH 
A

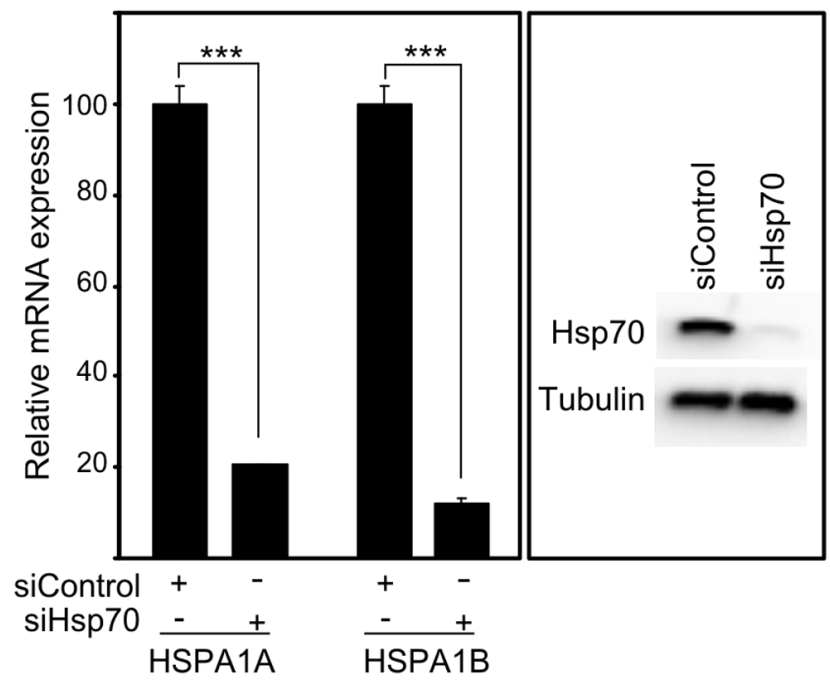

B

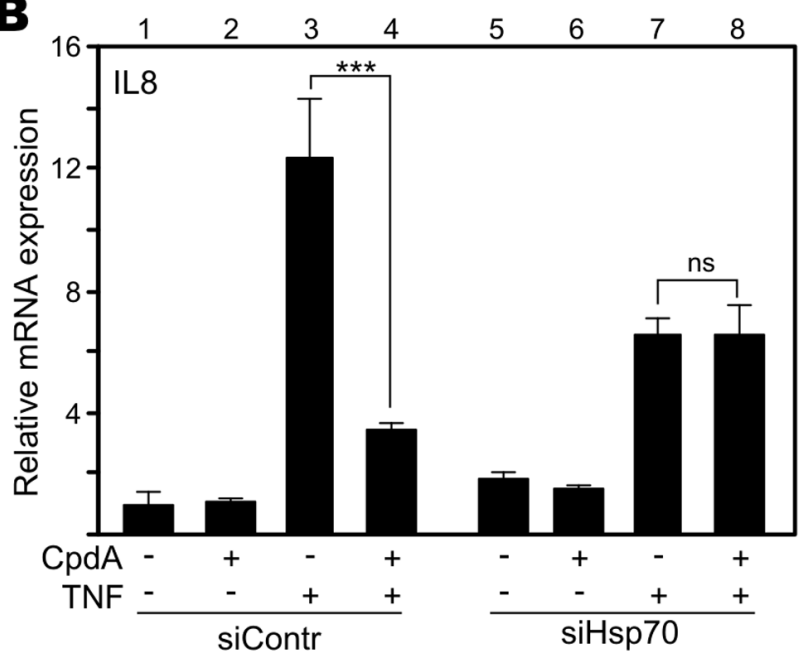

Figure 3. Hsp70 is required to allow the anti-inflammatory activity of Compound A. (A) A549 cells were transfected with siControl or siRNA targeting HSPA1A and HSPA1B (siHsp70). Total RNA or total protein extracts were prepared $48 \mathrm{~h}$ post transfection. Purified mRNA was subjected to RT-qPCR detecting HSPA1A or HSPA1B gene expression levels and specific results were normalized to housekeeping controls cyclophilin and $28 \mathrm{~S}$, as presented in the left panel. For siControl-transfected samples gene expression levels were set at $100 \%$. SiHsp70-transfected results were recalculated accordingly. Statistical analysis (unpaired t-test) was performed to show significant difference between siControl and siHsp70 conditions ( $\left.{ }^{* * *} p<0.001\right)$. In the right panel, total cell lysates were subjected to Western blot analysis to detect Hsp70 protein levels. Detection of tubulin served as loading control. (B) In parallel with (A), A549 cells were transfected with siControl or siHsp70. $41 \mathrm{~h}$ post transfection, cells were pretreated with Solv or CpdA (10 $\mu \mathrm{M})$ for $2 \mathrm{~h}$, after which ensued a $6 \mathrm{~h}$ TNF $(2000 \mathrm{IU} / \mathrm{ml})$ treatment. Purified mRNA was subjected to RT-qPCR detecting IL8 gene expression levels and specific results were normalized to housekeeping controls cyclophilin and 28S. The condition Solv (siControl) was set as 1 to allow ratio comparisons. Statistical analysis (ANOVA with Tukey's multiple comparison post test) was performed to show significant difference for selected pair wise comparisons (ns not significant; ** $\left.\mathrm{p}<0.01 ;{ }^{* * *} \mathrm{p}<0.001\right)$.

doi:10.1371/journal.pone.0069115.g003
mRNA levels served as control for input RNA and RT efficiency. From Figure 4A it is clear that in A549 cells heat shock clearly leads to an increase in HSPA1A gene transcription levels, which increases even more if cells are left to recover at $37^{\circ} \mathrm{C}$. Next, we found that CpdA indeed increases the expression of HSPA1A in A549 cells (Figure 4B). Of note, HSPAlA gene expression levels are even higher when the cells were stimulated with CpdA combined with heat shock than when the cells were induced with heat shock alone (Figure 4B), pointing to possible different and hence additive molecular induction mechanisms. Furthermore, CpdA could also elevate the mRNA levels transcribed of the related HSPA2 and HSPA6 genes (Figure S4). Concisely, CpdA can substantially elevate various Hsp70 gene expression levels in A549 cells. Further confirmation of these data was found in the human breast carcinoma cell line MCF-7 (Figure S5) and in vivo (Figure 4C). Indeed, complete skins from i.p. injected BALB/c mice were harvested after $24 \mathrm{~h}$ of induction. As expected, also in these samples, Compound A concentration-dependently enhances HSPA1A mRNA levels (Figure 4C), overall suggesting a cell- and species-independent effect.

\section{De novo Hsp70 production is not Necessary for CpdA's} anti-inflammatory Action Mechanism

Since CpdA is able to stimulate Hsp70 gene transcription, we went on to investigate whether CpdA-induced Hsp70 protein synthesis is required for the anti-inflammatory activity of CpdA. Hereto, we treated A549 cells with cycloheximide (CHX), an inhibitor of translational elongation and thus new protein synthesis and then analyzed the anti-inflammatory potential of CpdA toward the TNF-stimulated IL8 gene expression. Remarkably, the CpdA-mediated repression of TNF-induced IL8 gene expression was maintained when new protein synthesis was blocked via CHX (Figure 5A). Functionality of CHX could be confirmed by a Western blot experiment ran in parallel, in which we visualized the short-lived $\beta$-catenin protein (Figure S6).

Ensuing, we explored the effects of CpdA on Hsp70 protein levels. First, we confirmed that heat shock treatment elevated Hsp70 protein production in A549 cells (Figure 5B). In correspondence with Figure 4A, the detected Hsp70 Western blot signal was augmented by heat shock treatment and increased further, when cells were left to recover at $37^{\circ} \mathrm{C}$ (Figure 5B). However, contrary to our expectations, $6 \mathrm{~h}$ or $24 \mathrm{~h} \mathrm{CpdA}$ treatments of A549 cells did not appear to elevate Hsp70 protein levels (Figure 5C). Densitometric quantification analysis of multiple Western blot analyses clearly confirmed these results (Figure 5D). Moreover, independent Hsp70 ELISAs corroborated this yet again (Figure 5E). Similar data via Hsp70 ELISA were obtained from L929sA cell lysates (Figure S7). Regardless of the fact that Compound A appears unable to elevate the Hsp70 protein level, every assay shows a robust increase in $\mathrm{Hsp} 70$ protein levels after heat shock treatment.(Figure 5C-E, Figure S7).

To explore whether the lack of a CpdA-induced Hsp70 protein level rise can be attributed to a rapid degradation of the $\mathrm{Hsp} 70$ protein, we analyzed A549 and PC-3 cells cells using co-treatments with MG132, an inhibitor of proteasomal degradation. We could show that addition of MG132 does not allow for a CpdA-mediated increase in Hsp70 protein (Figure 6A). To investigate whether CpdA enforces a general block on translation, we analyzed the effects of CpdA on the protein levels of $\beta$-catenin, a protein with a short half-life of approximately $2-3 \mathrm{~h}$, depending on the cell type $[41,42,43]$ (Figure 6B). Treatment of A549 cells with CpdA does not result in a degradation of $\beta$-catenin, not even after a $48 \mathrm{~h}$ treatment with CpdA (Figure 6B). Similar results were obtained in PC-3 cells (Figure S8A). Additionally, we explored whether or not 


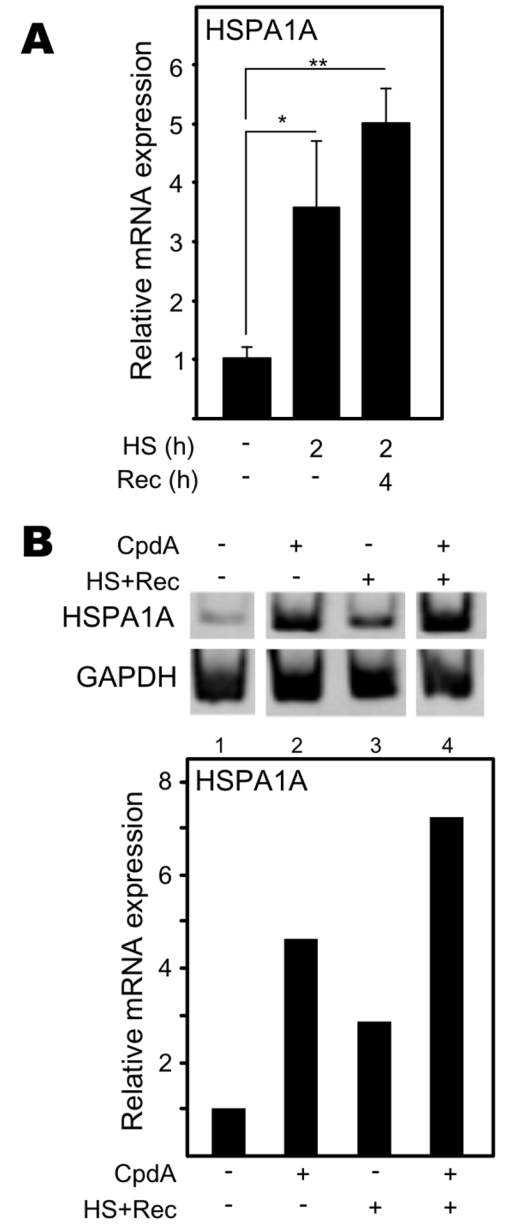

C

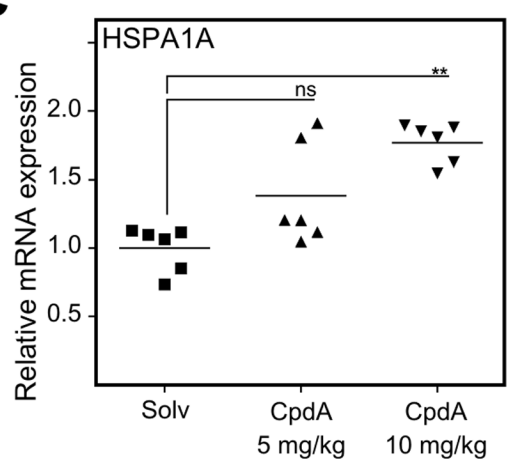

Figure 4. Compound A augments Hsp70 gene expression. (A) A549 cells were left untreated or were induced with heat shock (HS) at $43^{\circ} \mathrm{C}$ for $2 \mathrm{~h}$ either or not followed by $4 \mathrm{~h}$ recovery time (Rec) at $37^{\circ} \mathrm{C}$. Isolated total RNA was subjected to RT-qPCR for the detection of HSPA1A, normalized to cyclophilin housekeeping control. The noninduced condition was set as 1 to allow ratio comparisons. Statistical analysis (ANOVA with Tukey's multiple comparison post test) was performed for selected pair wise comparisons (ns not significant; ${ }^{*} p<0.05 ;{ }^{* *} p<0.01$ ). These results are representative of three independent experiments. (B) A549 cells, treated with solvent (Solv) or $\mathrm{CpdA}(10 \mu \mathrm{M})$, were either incubated at $37^{\circ} \mathrm{C}$ for 6 hours or subjected to the following temperature protocol : 2 hours at $37^{\circ} \mathrm{C}$ (pre-induction), followed by 2 hours at $43^{\circ} \mathrm{C}$ heat shock (HS) and lastly 2 hours at $37^{\circ} \mathrm{C}$ (recovery; Rec). Isolated total RNA was subjected to RT-PCR for the detection of HSPA1A and control GAPDH gene expression levels. The displayed bands were detected from one single gel. The respective bands were quantified using ImageJ software and normalized to GAPDH control expression levels. Solv was set as 1 and all other conditions were recalculated relative to this condition and expressed as relative mRNA expression level. The figure is representative for 2 independent experiments. (C) Eight week old female BALB/c mice were injected intraperitoneally with either PBS as a control or CpdA dissolved in PBS $(5 \mathrm{mg} / \mathrm{kg}$ or $10 \mathrm{mg} / \mathrm{kg})$ and $24 \mathrm{~h}$ later total skin samples were resected and their respective mRNA samples were subjected to RTqPCR analysis assaying for HSPA1A gene expression levels and normalized to RPL13a, HMBS and ACTB housekeeping controls. The non-induced condition was set as 1 to allow ratio comparisons. Statistical analysis (Mann Whitney-U-test) was performed for selected pair wise comparisons (ns not significant; ${ }^{* *} \mathrm{p}<0.01$ ). doi:10.1371/journal.pone.0069115.g004

CpdA could affect the expression levels of the constitutively expressed galactosidase reporter gene in stably transfected L929sA cells. As expected, CpdA does not significantly affect these galactosidase levels, again indicating that $\mathrm{CpdA}$ does not inhibit translation in general (Figure S8B).

In summary, the anti-inflammatory mechanism of CpdA does not appear to depend on de novo (Hsp70) protein synthesis.

\section{The Glucocorticoid Receptor Interacts with Hsp70 and Hsp90}

Mammalian Protein-Protein Interaction Trap (MAPPIT) is a two-hybrid interaction mapping technique based on the functional complementation of a type I cytokine receptor signaling pathway, using a STAT3-dependent luciferase reporter gene as a read-out. MAPPIT relies on a dysfunctional JAK-STAT signaling pathway, of which the activity is only restored when a protein-protein interaction between specific 'bait' and 'prey' chimeras occurs [44]. Since it operates in intact human cells, MAPPIT allows for analysis of protein:protein interactions under different physiological conditions, e.g. untreated versus DEX- or CpdA-treated cells. As expected, the interaction between unliganded GR $\alpha$ and Hsp90 or Hsp70 (Figure 7) yielded a strong signal in MAPPIT. These interactions were lost upon stimulation with DEX, as expected, but retained upon CpdA induction (Figure 7). There was no interaction (no signal) with the irrelevant bait, confirming that the observed interactions are indeed GR $\alpha$-specific.

These findings were verified via mass spectrometry analysis, using a shotgun proteomics approach, following the elution of immunoprecipitated Flag-tagged GR $\alpha$ that was overexpressed in HEK293T cells. Table 1 demonstrates that the number of identified MS/MS spectra for associated Hsp70 and Hsp90 proteins was comparable between solvent-treated and CpdAtreated cells (Table 1 and Table S2, listing per identified heat shock protein the corresponding peptides as well as the number of MS/MS spectra per identified peptide). Taken together, CpdA does not lead to dissociation of Hsp70 from the Glucocorticoid Receptor.

\section{Compound A Increases Hsp70 Promoter Activity Dose- dependently and Transiently}

Although an increase in Hsp70 protein does not seem to play a role in CpdA's overall anti-inflammatory mechanism, we were intrigued by the rarely reported gene stimulatory effect of CpdA. Therefore, we decided to explore the promoter regulation of Hsp70 in more detail. To directly investigate the effects of CpdA on Hsp70 promoter activity, we created a L929sA cell line in which the inducible murine Hsp70i-luc reporter gene construct was stably integrated in the genome. First, we tested for heat shock inducibility of the system and could confirm that the stably transfected mHsp70i-luc reporter gene construct responded positively to a heat shock stimulus (Figure 8A). Next, we evaluated 

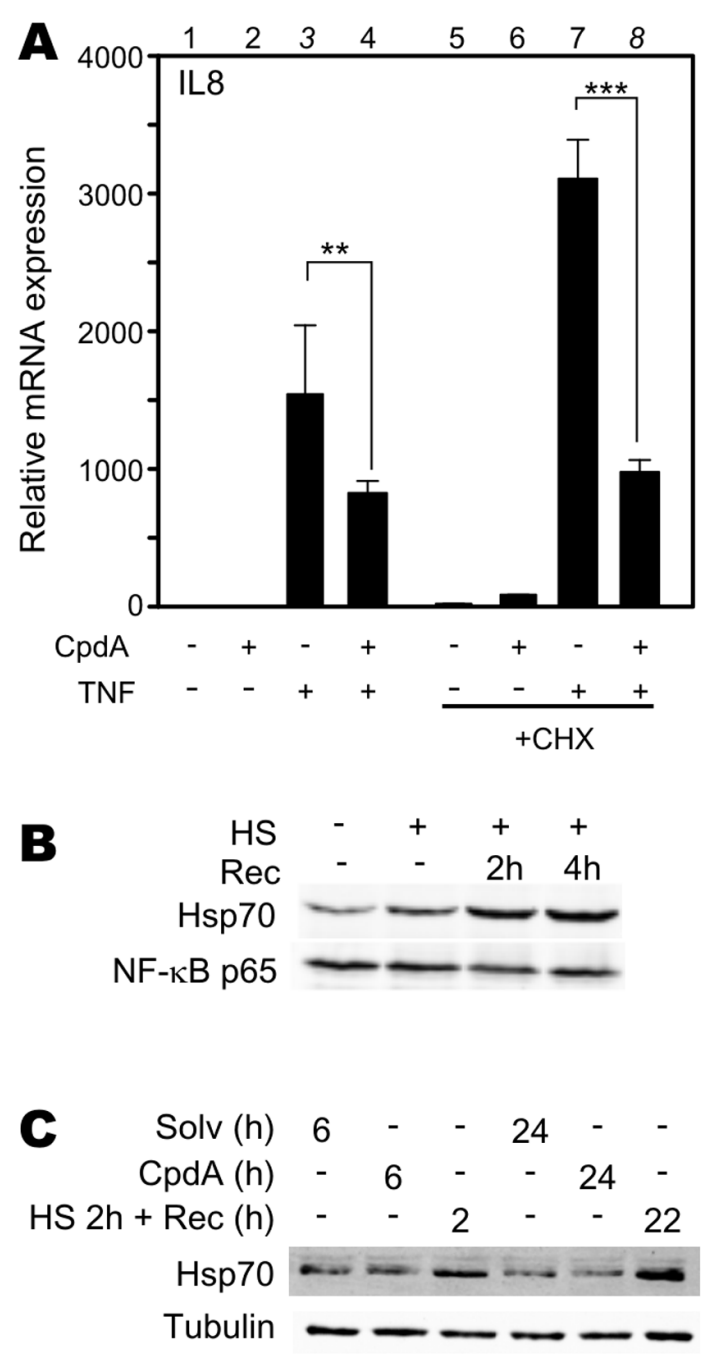
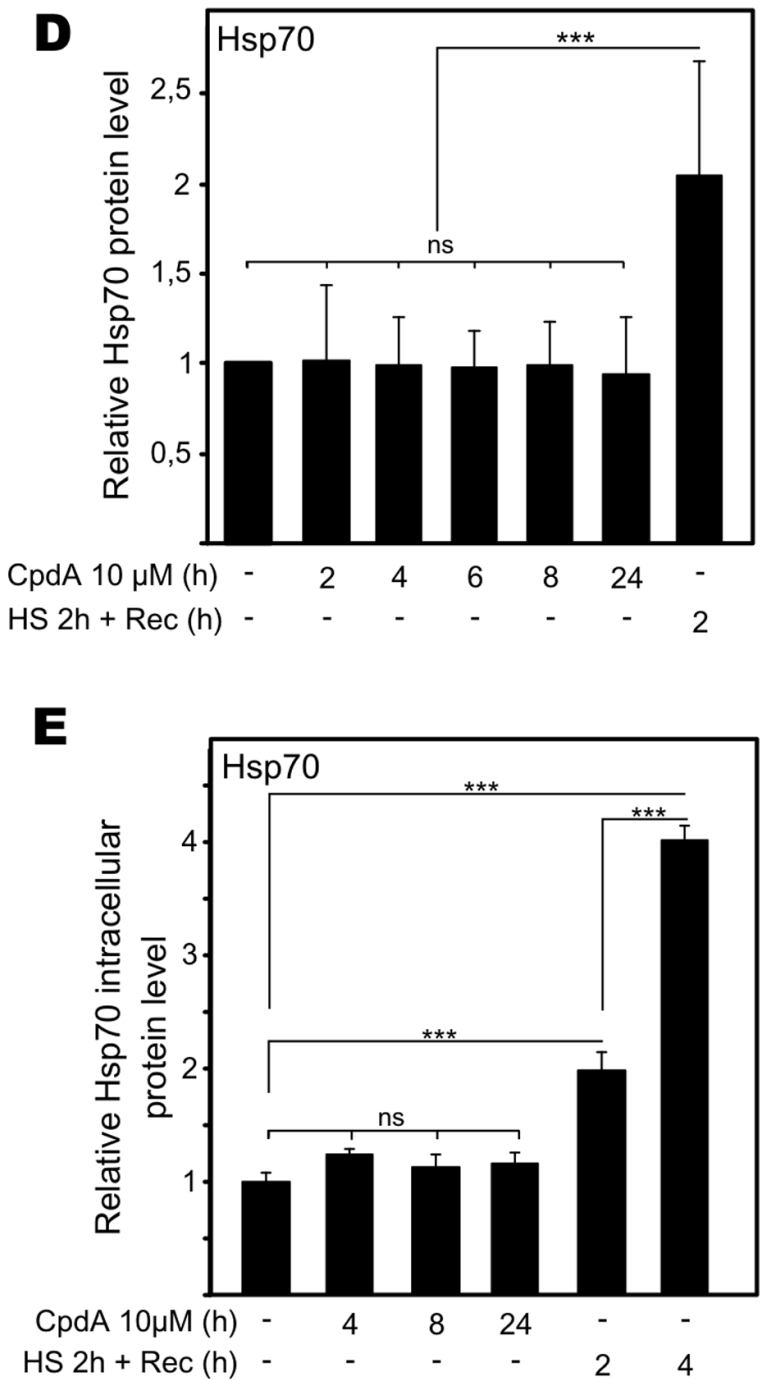

Figure 5. Hsp70 production is not necessary for CpdA's anti-inflammatory action mechanism. (A) A549 cells, starved for $48 \mathrm{~h}$, were left

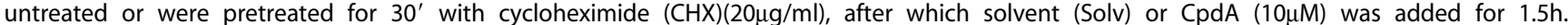
Subsequently, cells were incubated with TNF(2000IU/ml) for $5 \mathrm{~h}$. Isolated total mRNA was subjected to RT-qPCR detecting IL8, normalized to GAPDH levels. Solv was set as 1 and other conditions were recalculated accordingly. Statistical analysis (ANOVA with Tukey's multiple comparison post test) was performed for selected pair wise comparisons ( $\left.{ }^{* *} p<0.001 ;{ }^{* *} p<0.001\right)$. This figure is representative for 2 independent experiments. (B) A549 cells were heat-shocked (HS) at $43^{\circ} \mathrm{C}$ for $2 \mathrm{~h}$ either or not followed by recovery time (Rec) at $37^{\circ} \mathrm{C}$. (C) A549 cells were treated with Solv or CpdA (10 $\left.\mu \mathrm{M}\right)$ for $6 \mathrm{~h}$ or $24 \mathrm{~h}$ or heat-shocked at $43^{\circ} \mathrm{C}$ for $2 \mathrm{~h}$, after which cells were left to recover at $37^{\circ} \mathrm{C}$ for $2 \mathrm{~h}(\mathrm{HS}+\mathrm{Rec})$. (B)(C) Total cell protein extracts were subjected to Western blot analysis detecting Hsp70, with NF- $\mathrm{kB}$ p65 or tubulin as loading controls. These images are representative for at least 3 independent experiments. (D) shows the averaged band densitometric analysis (ImageJ) of 8 independent Hsp70 Western blot analyses. Specific Hsp70 signal was corrected for sample loading. Solv was set as 1 to allow ratio comparisons. Statistical analysis (ANOVA with Tukey's multiple comparison post test) was performed for selected pair wise comparisons (ns not significant; ${ }^{* * *} p<0.001$ ). (E) A549 cells were treated with solvent or $\mathrm{CpdA}(10 \mu \mathrm{M})$ for $4 \mathrm{~h}, 8 \mathrm{~h}$ or $24 \mathrm{~h}$ or heat-shocked at $43^{\circ} \mathrm{C}$ for $2 \mathrm{~h}$, after which cells were left to recover at $37^{\circ} \mathrm{C}$ for $2 \mathrm{~h}$ or $4 \mathrm{~h}(\mathrm{HS}+\mathrm{Rec})$. Total cell protein lysates were analyzed via Hsp70 ELISA. Statistical analysis (ANOVA with Tukey's multiple comparison post test) was performed for selected pair-wise comparisons (ns not significant; ${ }^{* * *} \mathrm{p}<0.001$ ). This figure represents averaged data of 4 independent experiments.

doi:10.1371/journal.pone.0069115.g005

the response of this inducible system to CpdA stimulation. We could demonstrate that CpdA concentration-dependently increases Hsp70 promoter activity, showing a significant elevation from a $5 \mu \mathrm{M}$ concentration onwards (Figure 8B). Furthermore, experimenting with variable induction times shows that a $6 \mathrm{~h} \mathrm{CpdA}$ treatment of the L929sA cells, stably transfected with mHsp70iluc, significantly augments $\mathrm{Hsp} 70$ promoter activity, whereas incubations with CpdA for $24 \mathrm{~h}$ or $48 \mathrm{~h}$ did not affect $\mathrm{Hsp} 70$ promoter activity (Figure $8 \mathrm{C}$ ). This transient time frame was confirmed when assaying A549 mRNA coding for HSPA1A (Figure 8D) and HSPA2 and HSPA6 (Figure S4), confirming and validating our earlier RT-PCR data (Figure 4B). Similar data were also obtained in PC-3 prostate adenocarcinoma cells (Figure 8E). In summary, Hsp70 promoter activity is concentration-dependently and transiently enhanced by CpdA in different cell lines and species.

CpdA stimulation of the Hsp70 gene promoter occurs via a GR-dependent mechanism

As CpdA is a selective GR modulator, driving GR into a monomeric formation [7], we wondered whether the stimulatory 
$\mathbf{A}$

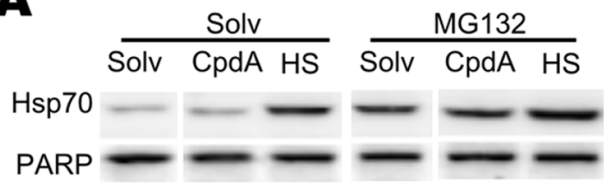

B

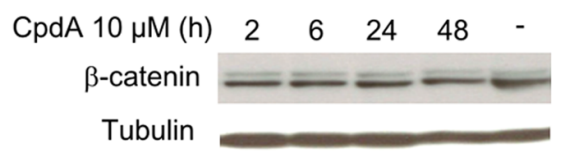

Figure 6. Compound A does not affect proteasomal degradation or translation. (A) A549 cells were preinduced with Solv or MG132 $(5 \mu \mathrm{M})$ for $1.5 \mathrm{~h}$. Subsequently, cells were stimulated with Solv or $\mathrm{CpdA}(10 \mu \mathrm{M})$ for $6 \mathrm{~h}$ or subjected to the following temperature protocol : 2 hours at $43^{\circ} \mathrm{C}$ followed by 2 hours at $37^{\circ} \mathrm{C}(\mathrm{HS}+\mathrm{Rec})$, as indicated. Total cell protein extracts were subjected to Western blot analysis detecting inducible Hsp70. Detection of PARP served as a loading control. The displayed bands were detected from one single membrane. (B) A549 cells were starved for $48 \mathrm{~h}$ in $0 \%$ DMEM, after which these cells were treated with solvent for $48 \mathrm{~h}$ or Compound $A$ $(\mathrm{CpdA})(10 \mu \mathrm{M})$ for $2 \mathrm{~h}, 6 \mathrm{~h}, 24 \mathrm{~h}$ or $48 \mathrm{~h}$. Total cell protein extracts were subjected to Western blot analysis detecting $\beta$-catenin. Tubulin detection served as a loading control.

doi:10.1371/journal.pone.0069115.g006

effect of CpdA on Hsp70 gene expression directly relies on the presence of GR. Hereto, we transfected A549 cells with siRNA targeting GR mRNA, resulting in a strong knockdown of GR mRNA and protein levels (Figure 9A). Analysis of HSPAlA gene expression levels in the non-targeting siControl transfected samples showed that induction with CpdA again is able to stimulate HSPA1A gene expression (Figure 9B), once more confirming and validating our RT-PCR data (Figure 4B). However, when we knocked down GR mRNA and protein levels, induction with CpdA failed to stimulate HSPA1A gene expression levels (Figure 9B). Based on these data, CpdA stimulation of HSPAlA gene expression can be considered as a GR-dependent phenomenon. Further analysis was performed at the promoter level via a GR-targeting Chromatin immunoprecipitation (ChIP), looking at promoter sites flanking the HSE locus in the HSPA1A gene promoter and the GRE locus in the glucocorticoid-induced leucine zipper (GILZ) gene promoter. Remarkably, the data revealed that CpdA did not direct the GR to the HSPAlA gene promoter, in contrast to DEX (Figure 9C). Focusing on a classical GRE-regulated GILZ promoter, a similar DEX-, but not CpdAinduced increase in GR occupancy was observed, as expected, confirming the functionality of our assay (Figure 9D). Also heat shock treatment failed to support GR occupancy at the HSPA1A or GILZ gene promoters (Figure 9C-D). In conclusion, CpdA stimulation of the Hsp70 gene promoter occurs via a GRdependent mechanism, but without GR occupancy at Hsp70coding gene promoters.

\section{Compound A Does not Activate HSF1}

As heat shock is known to stimulate $\mathrm{Hsp} 70$ gene expression via the activation of the transcription factor HSF1, and since GR seems to be an indirect contributor for CpdA-activated Hsp70 gene expression, we hypothesized CpdA may be able to exert effects on HSF1. Therefore, we analyzed via indirect immunofluorescence the endogenous HSF1 protein signal in A549 cells. As expected, we could show that heat shock treatment for $30 \mathrm{~min}$ (Figure S9) and $1 \mathrm{~h}$ induces the appearance of bright nuclear foci of HSF1, also called nuclear stress granules, indicated by white

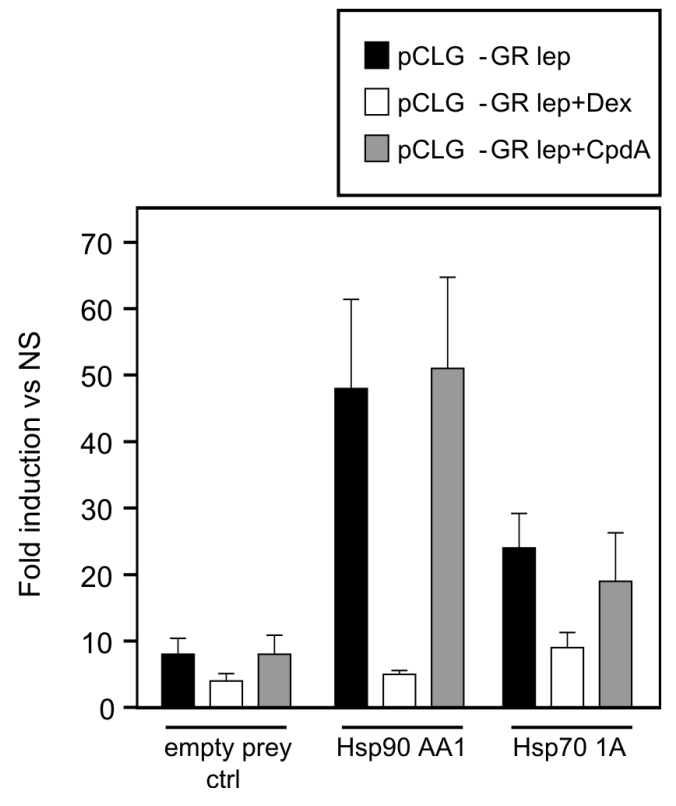

Figure 7. The glucocorticoid receptor interacts with $\mathrm{Hsp70}$ and Hsp90. HEK293T cells were transiently co-transfected with the MAPPIT GR $\alpha$-bait plasmid, the STAT3-responsive rPAP1-luci reporter plasmid and prey-plasmids as indicated. Empty prey is used as a negative control. Twenty-four hours after transfection cells were stimulated with leptin $(100 \mathrm{ng} / \mathrm{ml})$ and leptin in combination with DEX $(1 \mu \mathrm{M})$ or CpdA $(10 \mu \mathrm{M})$ for another $24 \mathrm{~h}$ or were left untreated (NS). Luciferase measurements were performed in triplicate. Data are expressed as mean fold induction (ratio stimulated/untreated).

doi:10.1371/journal.pone.0069115.g007

arrows (Figure 10A), indicative of an activated HSF1 [12,45]. In contrast, CpdA treatment for 30min, $1 \mathrm{~h}$ (Figure S9) and up to $4 \mathrm{~h}$ did not result in the aggregation of HSF1 in nuclear stress granules (Figure 10A). From Western blot analyses it also became clear that CpdA does not affect HSF1 cellular protein levels (Figure S10A-B). Moreover, CpdA does not shift the HSF1 band to a higher molecular weight, whereas heat shock treatment can induce a shift of HSF1, suggesting intense phosphorylation and thus activation (Figure S10A) [13,45]. Moreover, when investigating HSF1 recruitment to the proximal HSPAlA gene promoter via ChIP analysis, we could demonstrate that heat shock induces a significant increase in HSF1 recruitment at this site (Figure 10B). In contrast, CpdA did not significantly change HSF1 occupancy at the HSPAlA promoter (Figure 10B). As expected, the GC DEX did not affect basal recruitment of HSFl at the HSPAlA promoter. The specificity of the HSF1 signal was verified via analysis of binding to rabbit IgG. Taken together, CpdA does not stimulate HSF1 transcription factor activity, in contrast to heat shock treatment.

\section{Discussion}

The selective GR modulator GpdA (Figure 1A) is capable of efficaciously inhibiting NF- $\kappa \mathrm{B}$-driven gene expression while leaving GRE-regulated promoter activity unaffected (Figure 1) [5]. CpdA competes with DEX for GR binding, forcing GR into a monomer formation and evoking GR translocation into the nucleus in various cell lines [8]. The CpdA-mediated mechanism repressing NF- $\mathrm{KB}$-driven gene expression depends on the presence of GR, since CpdA's anti-inflammatory effect could not be observed in HEK293T cells devoid of a significant amount of 
A

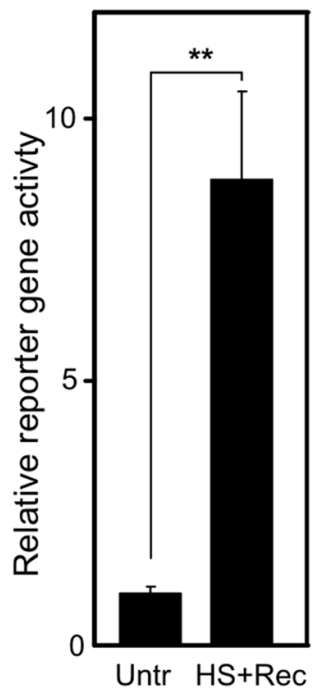

B

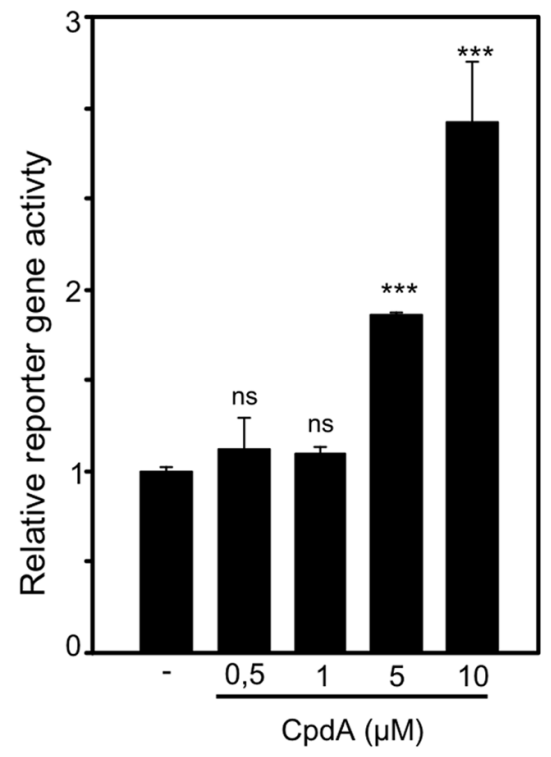

C

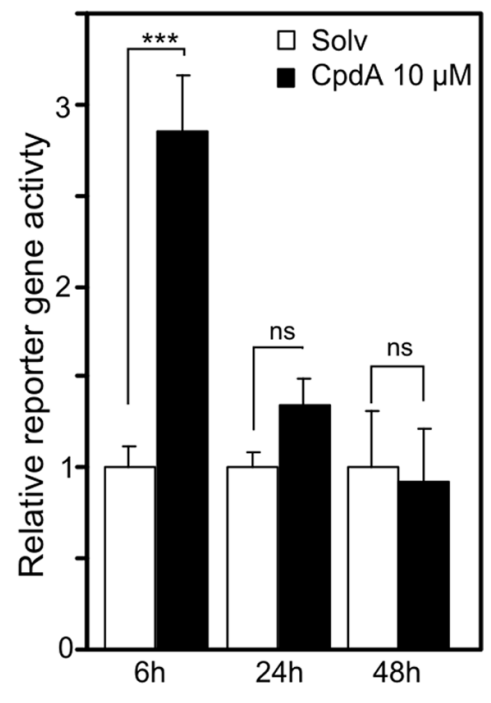

D

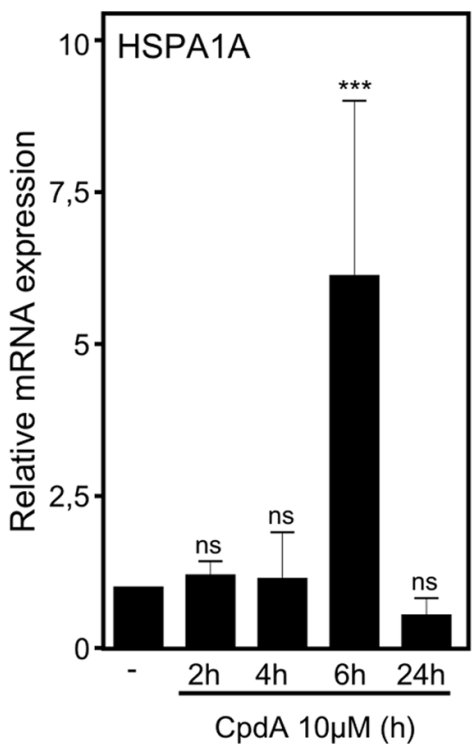

$\mathbf{E}$

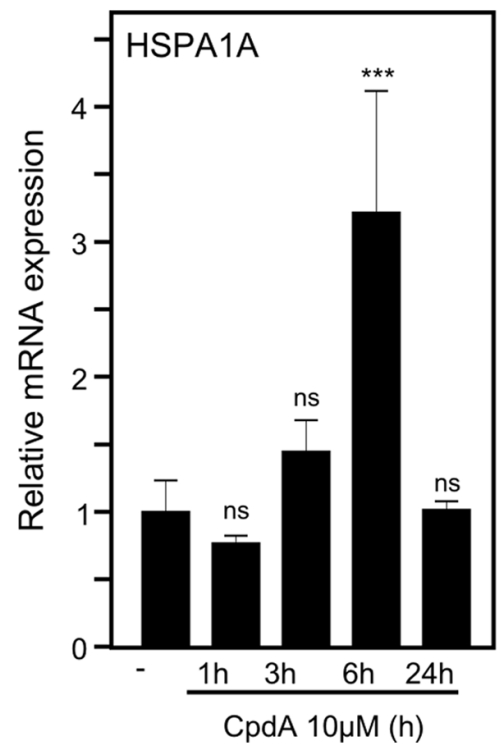

Figure 8. Compound A increases Hsp70 promoter activity dose-dependently and transiently. (A) L929sA cells, stably transfected with a $\mathrm{mHsp70i-luc} \mathrm{reporter} \mathrm{gene} \mathrm{construct,} \mathrm{were} \mathrm{left} \mathrm{untreated} \mathrm{(Untr)} \mathrm{or} \mathrm{were} \mathrm{stimulated} \mathrm{with} \mathrm{heat} \mathrm{shock} \mathrm{at} 43^{\circ} \mathrm{C}$ for $2 \mathrm{~h}$, followed by a recovery period of $2 \mathrm{~h}$ at $37^{\circ} \mathrm{C}(\mathrm{HS}+\mathrm{Rec})$. Normalized luciferase levels were presented as relative reporter gene activity with the condition 'Untr' set as 1 . Statistical analysis (unpaired t-test) was performed. This figure is representative for 6 independent experiments. (B) L929sA cells, stably transfected with mHsp70i-luc, were induced for $8 \mathrm{~h}$ with various concentrations of $\mathrm{CpdA}$, as indicated. All samples were controlled to a similar amount of solvent. This figure is representative for 4 independent experiments. (C) L929sA cells, stably transfected with mHsp70i-luc, were treated with solvent (Solv) or CpdA (10 $\mu$ M) for $6 \mathrm{~h}, 24 \mathrm{~h}$ or $48 \mathrm{~h}$. Data were presented as relative reporter gene activity with the Solv condition set as 1 . Statistical analysis (ANOVA with Tukey's multiple comparison post test) was performed to explore if Solv differs from CpdA treatment for each respective induction time. (D) A549 cells, were treated with solvent or $\mathrm{CpdA} 10 \mu \mathrm{M}$ for the indicated time period. Total cellular mRNA was subjected to RT-qPCR detecting gene expression levels for HSPA1A, normalized using housekeeping 36B4 and $\beta$-actin mRNA levels. Four independent experiments with slightly varying time kinetics all show comparable results. (E) PC-3 cells were starved for $48 \mathrm{~h}$ in $0 \%$ DMEM, after which these cells were left untreated or treated with Compound A (10 $4 \mathrm{M}$ ), as indicated. Purified mRNA was subjected to RT-qPCR detecting HSPA1A gene expression levels and specific results were normalized to housekeeping controls cyclophilin, GAPDH and 36B4. (B)(D)(E) Solv condition was set as 1 and results recalculated accordingly. Statistical analysis (ANOVA with Tukey's multiple comparison post test) was performed to compare with Solv (ns not significant; ${ }^{* *} p<0.01$; ${ }^{* *} p<0.001$ ).

doi:10.1371/journal.pone.0069115.g008 
$\mathbf{A}$

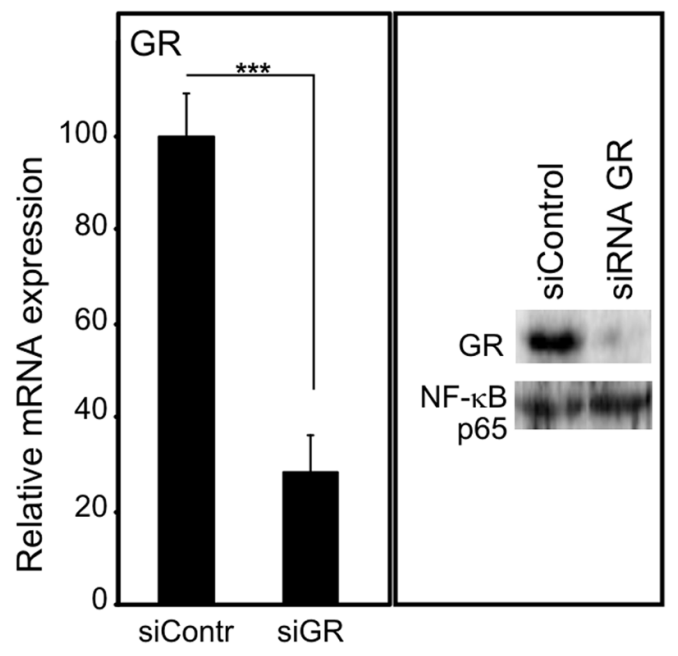

C

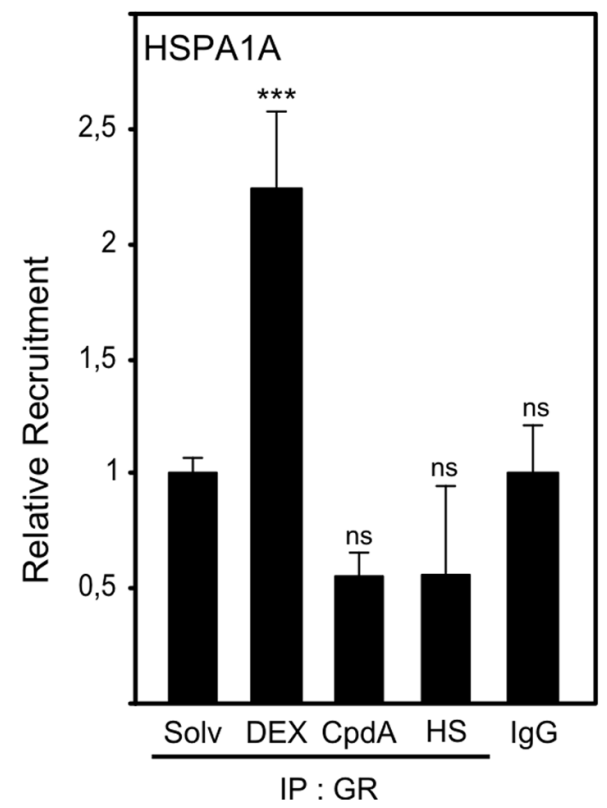

$\mathbf{B}$

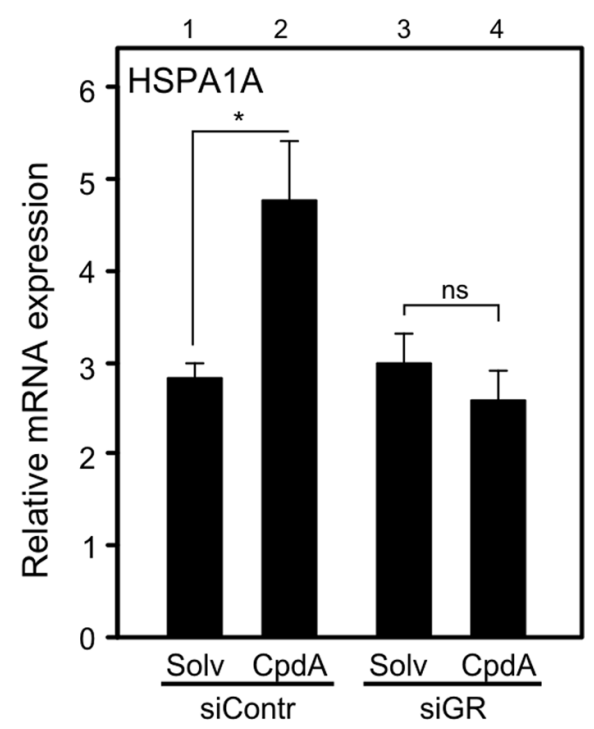

D

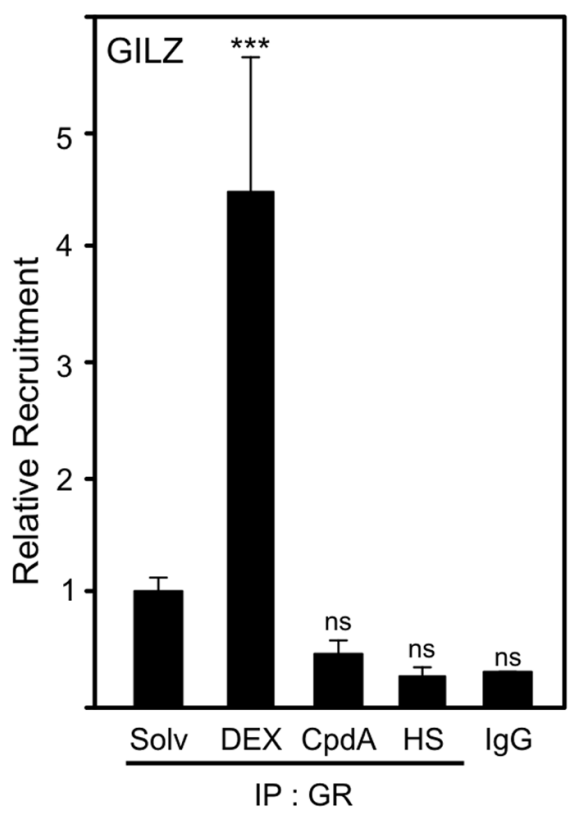

Figure 9. CpdA stimulation of the Hsp70 gene promoter occurs via a GR-dependent mechanism. (A) A549 cells were transfected with siControl or siRNA targeting GR (siGR). Total RNA or total protein extracts were prepared 48h post-transfection. In the left panel, purified mRNA was subjected to RT-qPCR detecting GR gene expression levels, normalized to housekeeping controls cyclophilin and 28S. For the siControl-transfected sample, signal was set at $100 \%$. Data from SiGR-transfected cells were recalculated accordingly. Statistical analysis (unpaired t-test) was performed to show significant difference between siControl and siGR conditions $\left({ }^{* * *} \mathrm{p}<0.001\right)$. In the right panel, total cell lysates were subjected to Western blot analysis to detect GR protein, with NF-kB p65 as a loading control. (B) In parallel with (A) A549 cells were transfected with siControl or siGR. 41h post transfection, cells were induced with Solv or $\mathrm{CpdA}(10 \mu \mathrm{M})$ for $8 \mathrm{~h}$. The derived purified mRNA was subjected to RT-qPCR detecting HSPA1A gene expression levels and specific results were normalized to housekeeping controls cyclophilin and 28S. The condition Solv (siControl) was set as 1 to allow ratio comparisons. Statistical analysis (ANOVA with Tukey's multiple comparison post test) was performed for selected pair wise comparisons (ns not significant; ${ }^{*} \mathrm{p}<0.05$ ). This experiment is representative for 2 independent experiments. (C) and (D) A549 cells, serum-starved for $48 \mathrm{~h}$ in $0 \%$ DMEM, were treated with Solv, Dex $(1 \mu \mathrm{M}), \mathrm{CpdA}(10 \mu \mathrm{M})$ for $2 \mathrm{~h}$, or exposed to a $43^{\circ} \mathrm{C}$ heat shock (HS) for $1 \mathrm{~h}$. Total cell extracts were subjected to a ChIP assay targeting GR. Ensuing, qPCR signal of immunoprecipitated HSPA1A and GILZ gene promoter fragments is presented relative to input data. Binding to rabbit IgG represents aspecific binding. Statistical analysis (ANOVA with Tukey's multiple comparison post test) was performed to show significant difference with the Solv condition (ns not significant; ${ }^{* * *} \mathrm{p}<0.001$ ). This experiment is representative for 2 independent experiments. doi:10.1371/journal.pone.0069115.g009 
$\mathbf{A}$
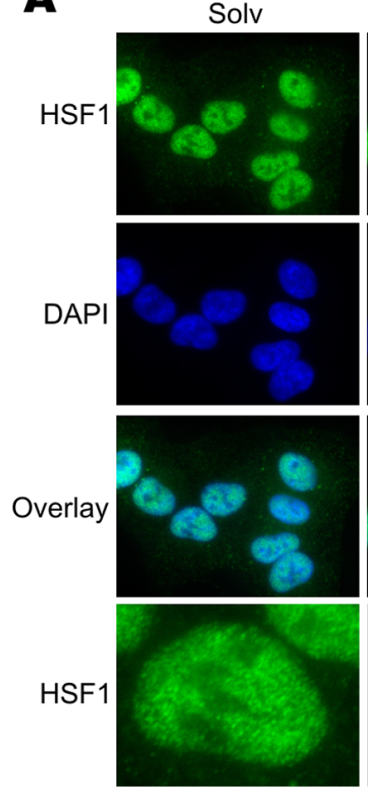

CpdA
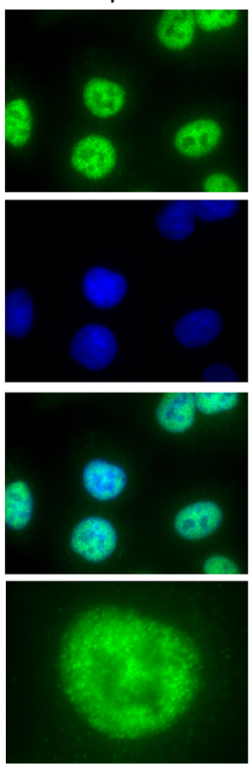

HS

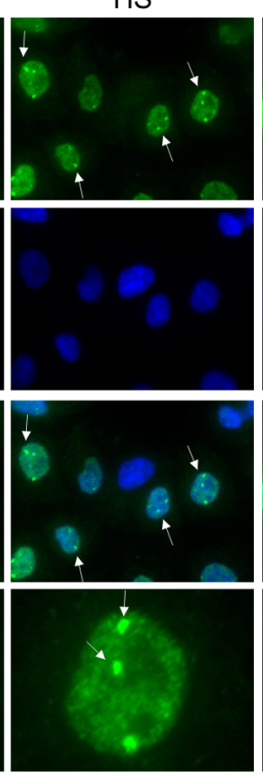

HS

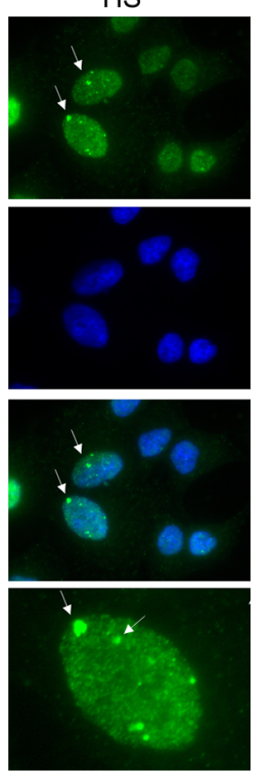

B

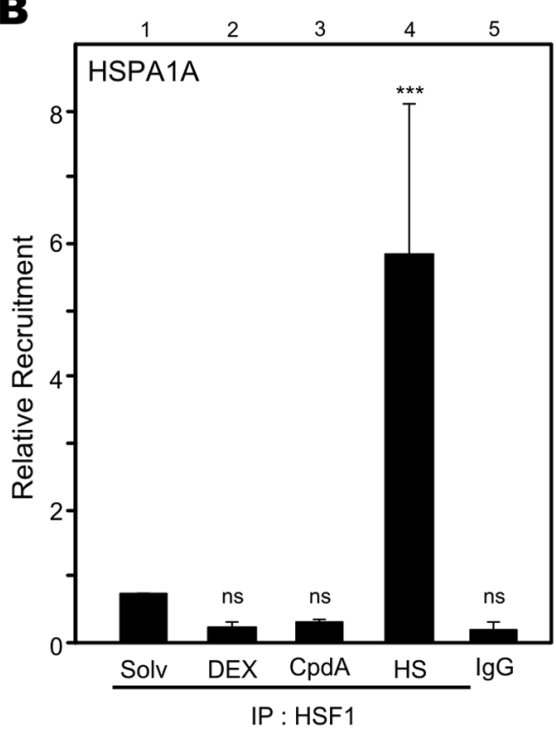

Figure 10. Compound A does not activate HSF1. (A) A549 cells, starved for 48h in Optimem, were treated with solvent (Solv) or CpdA (10 $\mu$ M) for $4 \mathrm{~h}$ or heat-shocked (HS) at $43^{\circ} \mathrm{C}$ for $1 \mathrm{~h}$. Via indirect immunofluorescence using an $\alpha$-HSF1 Ab, endogenous HSF1 was visualized (green) and DAPI staining indicates the nuclei of the cells (blue). We also present an overlay and in the panel below, we digitally zoom in on one cell. White arrow heads indicate nuclear stress granules or foci of HSF1. This experiment is representative for 2 independent experiments. (B) A549 cells, starved for $48 \mathrm{~h}$ in $0 \%$ DMEM, were treated with Solv, CpdA $(10 \mu \mathrm{M})$ or DEX $(1 \mu \mathrm{M})$ for $2 \mathrm{~h}$ or $\mathrm{HS}$ at $43^{\circ} \mathrm{C}$ for $1 \mathrm{~h}$. Total cell extracts were subjected to a ChIP assay targeting HSF1. Ensuing, qPCR signal of immunoprecipitated HSPA1A gene promoter fragments is presented relative to input data. Binding to rabbit IgG represents aspecific binding. Statistical analysis (ANOVA with Tukey's multiple comparison post test) was performed to show significant difference with the Solv condition (ns not significant; ${ }^{* * *} p<0.001$ ). This experiment is representative for 2 independent experiments. doi:10.1371/journal.pone.0069115.g010

endogenous GR [5], and was lost in FLS cells in which GR had been efficiently knocked down [39].

\section{Role of Hsp70 in CpdA's anti-inflammatory Mechanism}

Hsp70 and activated HSF1 are anti-inflammatory mediators targeting NF- $\mathrm{BB}$ in various cell systems $[17,18,37,46]$. Mechanistically, elevation of the Hsp70 levels targets IKK $\gamma$, resulting in a disruption of the IKK complex [18,37]. Although elevated Hsp70 levels can inhibit, but not abolish, I $\mathrm{KB} \alpha$ phosphorylation and does not affect $I \kappa B \alpha$ ubiquitination [18,38], heat shock induction leading to increased $\mathrm{Hsp} 70$ levels impairs $\mathrm{I} \kappa \mathrm{B} \alpha$ proteasomal degradation and limits the subsequent NF- $\mathrm{B}$ p65 translocation $[18,37,38]$. Additionally, heat shock can elevate $\mathrm{I} \kappa \mathrm{B} \alpha$ promoter activity and mRNA stability $[47,48]$. Furthermore, elevated Hsp70 levels can negatively affect the release of the pro-inflammatory high mobility group box 1 (HMGBl) [38]. Given the mechanistic resemblance between heat shock and CpdA, with respect to their effects on cytokine gene expression, $\mathrm{I} \kappa \mathrm{B} \alpha$ degradation and NF- $\kappa \mathrm{B}$ p65 nuclear translocation (Figure 2, Figure S2) in various cell systems $[39,40,49,50]$, we were not surprised to detect that CpdA can elicit a concentration-dependent, yet transient, rise in Hsp70coding mRNA levels and promoter activity (Figure 4, 8, Figure S4) in human A549 and PC-3 cells and murine L929sA cells. These findings could be confirmed in human MCF7 breast cancer cells (Figure S5) and skins of BALB/c mice (Figure 4C), indicating species-, cell- and tissue independence of this phenomenon. Knocking down Hsp70 abrogates the ability of CpdA to repress TNF-stimulated IL8 and IL6 gene expression (Figure 3, Figure S3). However, in spite of the clear effect of CpdA on Hsp70 promoter activity and gene expression, no CpdA-instigated elevation in Hsp70 protein was detected (Figure 5B-D, Figure
S7). Experiments with the translational elongation inhibitor CHX indicate that CpdA's anti-inflammatory mechanism does not require de novo protein synthesis (Figure 5A) and a persistent association was observed between pre-existing Hsp70 and CpdAactivated GR (Figure 7, Table 1, Table S2). Taken together, these results most likely point to a role of $\mathrm{Hsp} 70$ in the GR chaperone complex to mediate the 'reception' of CpdA by the GR-Hsp70 complex (Figure 7, Table 1, Table S2), additionally supporting the concept that the CpdA-regulated anti-inflammatory mechanism acts via GR binding and subsequent modulation of GR-dependent phenomena.

The underlying reason for the disconcordance between Hsp70 gene expression and Hsp70 protein production following CpdA treatment is currently unknown. Although secreted Hsp70 has immunomodulatory effects $[51,52,53]$ we were unable to find support for a CpdA- or heat shock-induced secreted Hsp70. Furthermore, we investigated whether a rapid proteasomal degradation of Hsp70 [54,55] could lie at the basis of the difference between protein versus mRNA and reporter gene activity results. As expected, MG132-mediated blocking of proteasomal degradation could elevate basal Hsp70 protein levels substantially, either via the inhibition of $\mathrm{Hsp} 70$ protein degradation $[54,55]$ or also via a HSF1-based stimulation of Hsp70 gene transcription $[56,57,58,59]$. However, the induction of Hsp70 by CpdA treatment in the presence of MG132 is not enhanced in comparison to the natural CpdA-stimulated fold induction of Hsp70 protein in the absence of MG132 (Figure 6A), indicating that the minor fold increase is not caused by a rapid turn-over of CpdA-induced Hsp70 protein. Furthermore, we could show that CpdA does not enforce a general block on translation as the translation of luciferase (Figure $8 \mathrm{~B}-\mathrm{C}$ ) and galactosidase (Figure 
$\mathrm{S} 8 \mathrm{~B}$ ) in various reporter gene assays is not blocked. Moreover, the protein level of $\beta$-catenin, a protein with a short half-life of approximately $2-3 \mathrm{~h}[41,42,43]$ shows no decline in response to CpdA, not even after 48h, in both A549 and PC-3 cells (Figure 6B, Figure S8A). However, the puzzling matter of a CpdA-induced rise in HSPA1A mRNA without the expected rise in Hsp70 protein remains. More than one hypothesis can account for this observation: for example, a sequence-specific inhibition of translation may occur or, alternatively, CpdA might elevate Hsp70 targeting miRNAs [60]. These possibilities would require extensive additional research. The consistent observation that CpdA can induce Hsp70 mRNA gene expression, without elevating Hsp70 protein levels makes us wonder what the precise role of this CpdA-stimulated Hsp70 mRNA might be. It is tempting to speculate that Hsp70 mRNA could serve as a cofactor, conform reports on the steroid receptor RNA activator SRA $[61,62,63]$, which acts as a steroid receptor cofactor. Similar to Hsp70, some isoforms of SRA do code for a functional protein, i.e. SRAP. Finally and less exciting, the CpdA-induced production of Hsp70 mRNA may be an unintentional by-product of CpdAmodulated mechanisms. Albeit the question remains why the cell would spend energy on transcribing a mRNA with no further functional implication. Additional research could shed more light on this matter.

\section{CpdA-mediated Hsp70 Gene Transcription}

Stimulation with CpdA combined with heat shock results in higher HSPA1A gene expression levels, than in solely heat shockor CpdA-induced cells (Figure 4B). This additional Hsp70 mRNA increase could therefore suggest alternative Hsp70 promoter activation mechanisms. The latter hypothesis, potentially implying that heat shock-inducible HSF1 does not act as a mediator of CpdA-mediated Hsp70 upregulation, is clearly supported by the following arguments. First, in contrast to heat shock treatment, CpdA does not enhance HSFl recruitment to the HSPAlA promoter (Figure 10B). Second, CpdA does not trigger the formation of nuclear stress granules of HSF1, which are indicative for heat shock-induced and activated HSF1 [12,45] (Figure 10A). In addition, a second mechanistic aspect of the CpdA-mediated Hsp70 increase, was revealed upon investigating GR dependence. Our results strongly suggest that the presence of GR is an absolute requirement for the CpdA-instigated HSPAlA mRNA upregulation (Figure 9B). However, the involvement of GR does not coincide with a recruitment of GR to the HSPA1A gene promoter, suggesting that GR might act as a mediator rather than an effector. Interestingly, it has been described that GCs can repress heat shock-induced Hsp70 gene expression [64,65], via the interference of GC-activated GR with the recruitment of the transcription factor HSF1 to the proximal HSE-elements in the Hsp70 promoter [65]. These reports provide the context for the observed DEX-mediated recruitment of GR to the HSPA1A gene promoter (Figure 9C). Although stimulation of Hsp70 promoter activity by CpdA is GR-dependent, this mechanism is most likely not a classical GR dimer-driven, GRE-regulated transactivation as CpdA does not mediate GRE-regulated transcription, does not instigate GR dimerization and actively drives GR into a monomer formation [5,7].

To sum up, CpdA and heat shock use different signalling pathways to induce Hsp70 gene expression. Whereas heat shock activates HSF1, which acts as a transcription factor initiating Hsp70 gene expression, CpdA does not induce HSF1 activation. Additionally, CpdA necessitates the GR to be able to trigger Hsp70 gene expression.
In conclusion, in resemblance to the established anti-inflammatory effect of $\mathrm{Hsp} 70$ via halting TNF-stimulated I $\kappa \mathrm{B} \alpha$ degradation and NF- $\kappa \mathrm{B}$ p65 translocation, we could show that CpdA partially hampers TNF-stimulated I $\mathrm{B} \alpha$ degradation and NF- $\kappa \mathrm{B}$ p65 translocation. Correspondingly, CpdA enhances Hsp70 gene promoter activities and transcription, yet without producing additional Hsp70 protein. CpdA's anti-inflammatory mechanism does not require new protein synthesis and thus new Hsp70 protein production. Nevertheless, the cellular presence of Hsp70 mRNA and protein, most likely as the GR-interacting chaperone, remains crucial for CpdA's ability to repress NF- $\mathrm{BB}$-driven gene expression. Mechanistically, the selective GR modulator CpdA enhances Hsp70 promoter activity via a HSF1-independent and GR-dependent mechanism, whereas heat shock induces a rise in Hsp70 production via a HSF1-dependent and GR-independent mechanism. These data further support the hypothesis that CpdA is a dissociative modulator of GR, utilizing GR to repress proinflammatory promoter activation.

\section{Acknowledgments}

The authors would like to thank I Vanherpe, D. Bracke, B. Gilbert and $\mathrm{J}$ Thommis for their excellent technical assistance. Additionally, we thank C. Libert for critical reading of the original manuscript.

\section{Supporting Information}

Figure S1 Both Compound $A$ and heat shock diminish IL6 gene expression. (A) A549 cells, starved for 48h, were pretreated for $1.5 \mathrm{~h}$ with solvent (Solv), DEX $(1 \mu \mathrm{M}), \operatorname{CpdA}(10 \mu \mathrm{M})$ or subjected to heat shock treatment $\left(1 \mathrm{~h}\right.$ at $43^{\circ} \mathrm{C}$ and $30^{\prime}$ recovery at $\left.37^{\circ} \mathrm{C}\right)$, ensued with TNF $(2000 \mathrm{IU} / \mathrm{ml})$ for $5.5 \mathrm{~h}$. Isolated total RNA was subjected to RT-qPCR assaying IL6 mRNA levels, normalized to cyclophilin household gene mRNA levels. The TNF condition was set at 100 and results were recalculated accordingly. These results are representative of 2 independent experiments. Statistical analysis (ANOVA and Tukey multiple comparison post test) were performed for selected pair-wise comparisons.

(TIF)

Figure S2 Compound A diminishes IKB $\alpha$ degradation and NF-кB translocation. (A) L929sA cells, starved for 48h, were pretreated for $2 \mathrm{~h}$ with solvent (Solv), DEX $(1 \mu \mathrm{M})$ or CpdA $(10 \mu \mathrm{M})$, after which TNF $(2000 \mathrm{IU} / \mathrm{ml})$ was added as indicated. Western blot analysis of total cells lysates detects $\mathrm{I} \kappa \mathrm{B} \alpha$ protein, with NF- $\mathrm{BB}$ p65 as loading control. This figure is representative for 2 independent experiments. (B) L929s A cells, starved for $48 \mathrm{~h}$ in Optimem, were pretreated for $2 \mathrm{~h}$ with Solvent or CpdA $(10 \mu \mathrm{M})$. Subsequently, TNF $(2000 \mathrm{IU} / \mathrm{ml})$ was added for $30^{\prime}$, where indicated. After washing, fixation, and permeabilization, indirect immunofluorescence detects endogenous NF-кB p65. DAPI staining indicates the nuclei. Additionally, we present overlays. (TIF)

Figure S3 Hsp70 is required to allow the anti-inflammatory activity of Gompound A. A549 cells were transfected with siControl or siRNA targeting HSPAlA and HSPAlB (siHsp70). 41h post transfection, cells were pretreated with Solv or CpdA $(10 \mu \mathrm{M})$ for $2 \mathrm{~h}$, after which ensued a $6 \mathrm{~h}$ TNF (2000IU/ $\mathrm{ml}$ ) treatment. Total RNA extracts were prepared. Purified mRNA was subjected to RT-qPCR detecting IL6 gene expression levels and specific results were normalized to housekeeping controls cyclophilin and 28S. The condition Solv (siControl) was set as 1 to allow ratio comparisons. Statistical analysis (ANOVA with Tukey's multiple comparison post test) was performed to 
show significant difference for selected pair wise comparisons (ns not significant; $* * \mathrm{p}<0.01)$.

(TIF)

Figure S4 Compound A augments Hsp70 gene expression. A549 cells, were treated with solvent or CpdA $10 \mu \mathrm{M}$ for the indicated time period. Total cellular mRNA was subjected to RTqPCR detecting gene expression levels for HSPA2 or HSPA6 (as indicated), normalized using housekeeping 36B4 and $\beta$-actin mRNA levels. The Solv condition was set as 1 and results recalculated accordingly. Statistical analysis (ANOVA with Tukey's multiple comparison post test) was performed to compare with Solv (ns not significant; ** $\mathrm{p}<0.01$ ). Three independent experiments with slightly varying time kinetics all show comparable results. (B) MCF-7 breast cancer cells

(TIF)

Figure S5 GpdA can elevate Hsp70 gene expression levels in MCF7 cells. (A) MCF7 cells were pretreated with solvent or CpdA $(10 \mu \mathrm{M})$ for $8 \mathrm{~h}$. Total RNA was reverse transcribed and HSPA1A and housekeeping GAPDH mRNA levels were determined via semi-quantitative PCR visualized on a $2 \%$ agarose gels. The displayed bands were detected from one single gel. (B) MCF7 cells were assayed via the 'GEarray $Q$ series Analysis with Human Stress and Toxicity pathway' (SABiosciences). Cells were treated with solvent or CpdA $(10 \mu \mathrm{M})$ for $8 \mathrm{~h}$. Total RNA was isolated and reverse transcribed to hybridize labeled cDNA to Human Stress and Toxicity GEA array membranes. Results, visualized via Phospho-Imager, were quantified and controlled for by housekeeping genes. Effects of CpdA are presented as 'fold induction'.

(TIF)

Figure S6 Control of CHX functionality. A549 cells, starved for $48 \mathrm{~h}$, were left untreated or were treated for $7 \mathrm{~h}$ with cycloheximide (CHX) $(20 \mu \mathrm{g} / \mathrm{ml})$. Total cell protein extracts were subjected to Western blot analysis detecting $\beta$-catenin and an aspecific band serves as a loading control. (TIF)

Figure S7 CpdA does not elevate the Hsp70 protein level in L929sA cells. L929sA cells were treated with solvent or CpdA $(10 \mu \mathrm{M})$ for $4 \mathrm{~h}, 8 \mathrm{~h}$ or $24 \mathrm{~h}$ or heat-shocked at $43^{\circ} \mathrm{C}$ for $2 \mathrm{~h}$, after which cells were left to recover at $37^{\circ} \mathrm{C}$ for $2 \mathrm{~h}$ (HS+Rec). Total cell protein lysates were analyzed via Hsp70 ELISA. Statistical analysis (ANOVA with Tukey's multiple comparison post test) was performed for selected pair-wise comparisons (ns not significant; $* * p<0.01$ ). This figure represents averaged data of 2 independent experiments.

(TIF)

Figure S8 Compound A does not block translation. (A) PC-3 cells were starved for 48h in 0\% DMEM, after which these cells were treated with solvent for $48 \mathrm{~h}$ or Compound A (CpdA) $(10 \mu \mathrm{M})$ for $2 \mathrm{~h}, 6 \mathrm{~h}, 24 \mathrm{~h}$ or $48 \mathrm{~h}$. Total cell protein extracts were subjected to Western blot analysis detecting $\beta$-catenin. Tubulin detection served as a loading control. (B) L929sA cells, stably transfected with $\mathrm{p}(\mathrm{IL} 6 \kappa \mathrm{K})_{3} 50$ hu.IL6P-luc+, were left untreated $(\mathrm{NI})$, or were treated with solvent (Solv), or CpdA $(0.1 \mu \mathrm{M}, 1 \mu \mathrm{M}$ or $10 \mu \mathrm{M})$ for $8 \mathrm{~h}$. The relative activity of the constitutively expressed galactosidase ( $\beta$-gal) controls were presented as relative reporter gene activity with the condition Solv set at 100. All other conditions were recalculated accordingly. Statistical analysis (ANOVA with Tukey's multiple comparison post test) was performed (ns not significant).

(TIF)
Figure S9 Heat shock stimulates HSF1 heat shock granules, but GpdA does not. A549 cells, starved for $48 \mathrm{~h}$ in Optimem, were treated with solvent (Solv) for 60 minutes or CpdA $(10 \mu \mathrm{M})$ for 30 or 60 minutes. Alternatively, cells were heatshocked (HS) at $43^{\circ} \mathrm{C}$ for 30 minutes. Via indirect immunofluorescence using an $\alpha$-HSF1 Ab, endogenous HSF1 was visualized (green) and DAPI staining indicates the nuclei of the cells (blue). We also present an overlay and in the below panel, we digitally zoom in on one cell. White arrow heads indicate nuclear stress granules or foci of HSF1. This experiment is representative for 2 independent experiments.

(TIF)

Figure S10 GpdA does not augment the HSF1 level, nor does it shift the band hight. (A) A549 cells were treated with Solv, CpdA $(10 \mu \mathrm{M})$ or DEX $(1 \mu \mathrm{M})$ for $2,4,6$ or 24 hours. Alternatively, cells were heat-shocked at $43^{\circ} \mathrm{C}$ for $2 \mathrm{~h}$, after which cells were left to recover at $37^{\circ} \mathrm{C}$ for $2 \mathrm{~h}$ (HS+Rec). Total cell protein extracts were subjected to Western blot analysis detecting HSF1, with NF- $\kappa \mathrm{B}$ p65 as a loading control. This image is representative for 2 independent experiments. (B) shows the averaged band densitometric analysis (Image J) of 2 independent HSF1 Western blot analyses. Specific HSF1 signal was corrected for sample loading. Solv was set as 1 to allow ratio comparisons. Statistical analysis (ANOVA with Tukey's multiple comparison post test) was performed for selected pair wise comparisons (ns not significant).

(TIF)

Table S1 Detailed siRNA information (Dharmacon, Thermo Fischer).

(DOCX)

Table S2 List of identified heat shock proteins and their corresponding peptides. HEK293T cells were transfected with Flag-hGR $\alpha$ via calcium phosphate and following stimulation with either solvent (NI) or 10 $\mu \mathrm{M}$ CpdA (CpdA), immunoprecipitated using Flag beads (plasmid and methodology described in [7]. Two identical set-ups were done in parallel, yet, using two different elution methods, via $\mathrm{NH}_{4} \mathrm{OH}$, as indicated, or via the Flag peptide (FLAG, $100 \mu \mathrm{g} / \mathrm{ml}$ ). The identified heat shock proteins are listed and, per protein, the corresponding peptides (at 99\% confidence settings) are shown (note that Mox indicates methionine-sulfoxide (oxidation) and $\mathrm{Q}<\mathrm{Pyr}>$ indicates N-terminal pyroglutamic acid modification). The number of MS/MS spectra recorded per identified peptide is indicated.

(DOCX)

Materials and Methods S1 All materials and methods, as described in the manuscript are also valid for the supporting information figures S1-S10 and tables S1 and S2. Additional materials en methods to understand the supporting information figures and tables are added as a supporting file.

(DOCX)

\section{Author Contributions}

Conceived and designed the experiments: IMB RH VG WD WVB GH KDB MB SL KG GD JT. Performed the experiments: IMB ZD RH AAB MD DC SD NB BR WVB KDB GD. Analyzed the data: IMB ZD RH AAB MD WD WVB KDB DC SD NB BR KG SL. Contributed reagents/ materials/analysis tools: WVB SL JT KG KDB MB GH WD. Wrote the paper: IMB KDB. Wrote about LC-MS/MS: BR KG. Wrote about MAPPIT: SD SL. Edited the manuscript: IB KDB ZD RH AAB MD DC SD NB BR SL MB JT WD KG WVB GH. 


\section{References}

1. Hayden MS, Ghosh S (2008) Shared principles in NF-kappaB signaling. Cell 132: $344-362$

2. Beck IM, Vanden Berghe W, Vermeulen L, Yamamoto KR, Haegeman G, et al. (2009) Crosstalk in inflammation: the interplay of glucocorticoid receptorbased mechanisms and kinases and phosphatases. Endocr Rev 30: 830-882.

3. Smith DF, Toft DO (2008) Minireview: the intersection of steroid receptors with molecular chaperones: observations and questions. Mol Endocrinol 22: 2229 2240.

4. Schacke H, Docke WD, Asadullah K (2002) Mechanisms involved in the side effects of glucocorticoids. Pharmacol Ther 96: 23-43.

5. De Bosscher K, Vanden Berghe W, Beck IM, Van Molle W, Hennuyer N, et al. (2005) A fully dissociated compound of plant origin for inflammatory gene repression. Proc Natl Acad Sci U S A 102: 15827-15832.

6. Chen W, Dang T, Blind RD, Wang Z, Cavasotto CN, et al. (2008) Glucocorticoid receptor phosphorylation differentially affects target gene expression. Mol Endocrinol 22: 1754-1766.

7. Dewint P, Gossye V, De Bosscher K, Vanden Berghe W, Van Beneden K, et al. (2008) A plant-derived ligand favoring monomeric glucocorticoid receptor conformation with impaired transactivation potential attenuates collageninduced arthritis. J Immunol 180: 2608-2615.

8. De Bosscher K, Beck IM, Haegeman G (2010) Classic glucocorticoids versus non-steroidal glucocorticoid receptor modulators: survival of the fittest regulator of the immune system? Brain Behav Immun 24: 1035-1042.

9. Schäcke H, Docke WD, Asadullah K (2002) Mechanisms involved in the side effects of glucocorticoids. Pharmacol Ther 96: 23-43.

10. Liu H, Lightfoot R, Stevens JL (1996) Activation of heat shock factor by alkylating agents is triggered by glutathione depletion and oxidation of protein thiols. J Biol Chem 271: 4805-4812.

11. Ritossa F (1996) Discovery of the heat shock response. Cell Stress Chaperones 1: 97-98.

12. Jolly C, Vourc'h C, Robert-Nicoud M, Morimoto RI (1999) Intron-independent association of splicing factors with active genes. J Cell Biol 145: 1133-1143.

13. Pirkkala L, Nykanen P, Sistonen L (2001) Roles of the heat shock transcription factors in regulation of the heat shock response and beyond. FASEB J 15: 11181131.

14. Ostling P, Bjork JK, Roos-Mattjus P, Mezger V, Sistonen L (2007) Heat shock factor 2 (HSF2) contributes to inducible expression of hsp genes through interplay with HSF1. J Biol Chem 282: 7077-7086.

15. Sistonen L, Sarge KD, Morimoto RI (1994) Human heat shock factors 1 and 2 are differentially activated and can synergistically induce hsp70 gene transcription. Mol Cell Biol 14: 2087-2099.

16. Van Molle W, Wielockx B, Mahieu T, Takada M, Taniguchi T, et al. (2002) HSP70 protects against TNF-induced lethal inflammatory shock. Immunity 16 : 685-695.

17. Malhotra V, Wong HR (2002) Interactions between the heat shock response and the nuclear factor-kappa B signaling pathway. Crit Care Med 30: S89-95.

18. Weiss YG, Bromberg Z, Raj N, Raphael J, Goloubinoff P, et al. (2007) Enhanced heat shock protein 70 expression alters proteasomal degradation of IkappaB kinase in experimental acute respiratory distress syndrome. Crit Care Med 35: 2128-2138.

19. Lieber M, Smith B, Szakal A, Nelson-Rees W, Todaro G (1976) A continuous tumor-cell line from a human lung carcinoma with properties of type II alveolar epithelial cells. Int J Cancer 17: 62-70.

20. Kaighn ME, Narayan KS, Ohnuki Y, Lechner JF, Jones LW (1979) Establishment and characterization of a human prostatic carcinoma cell line (PC-3). Invest Urol 17: 16-23.

21. Vanhaesebroeck B, Van Bladel S, Lenaerts A, Suffys P, Beyaert R, et al. (1991) Two discrete types of tumor necrosis factor-resistant cells derived from the same cell line. Cancer Res 51: 2469-2477.

22. Vanden Berghe W, Plaisance S, Boone E, De Bosscher K, Schmitz ML, et al. (1998) p38 and extracellular signal-regulated kinase mitogen-activated protein kinase pathways are required for nuclear factor-kappaB p65 transactivation mediated by tumor necrosis factor. J Biol Chem 273: 3285-3290.

23. Plaisance S, Vanden Berghe W, Boone E, Fiers W, Haegeman G (1997) Recombination signal sequence binding protein Jkappa is constitutively bound to the NF-kappaB site of the interleukin-6 promoter and acts as a negative regulatory factor. Mol Cell Biol 17: 3733-3743.

24. Vanden Berghe W, Francesconi E, De Bosscher K, Resche-Rigon M, Haegeman G (1999) Dissociated glucocorticoids with anti-inflammatory potential repress interleukin-6 gene expression by a nuclear factor-kappaBdependent mechanism. Mol Pharmacol 56: 797-806.

25. Woo SK, Lee SD, Na KY, Park WK, Kwon HM (2002) TonEBP/NFAT5 stimulates transcription of HSP70 in response to hypertonicity. Mol Cell Biol 22: 5753-5760.

26. Yan J, Li Q Lievens S, Tavernier J, You J (2010) Abrogation of the Brd4positive transcription elongation factor $\mathrm{B}$ complex by papillomavirus $\mathrm{E} 2$ protein contributes to viral oncogene repression. J Virol 84: 76-87.

27. Eyckerman S, Verhee A, der Heyden JV, Lemmens I, Ostade XV, et al. (2001) Design and application of a cytokine-receptor-based interaction trap. Nat Cell Biol 3: 1114-1119.
28. Lamesch P, Li N, Milstein S, Fan C, Hao T, et al. (2007) hORFeome v3.1: a resource of human open reading frames representing over 10,000 human genes. Genomics 89: 307-315.

29. Lievens S, Vanderroost N, Defever D, Van der Heyden J, Tavernier J (2012) ArrayMAPPIT: a screening platform for human protein interactome analysis. Methods Mol Biol 812: 283-294.

30. Eyckerman S, Broekaert D, Verhee A, Vandekerckhove J, Tavernier J (2000) Identification of the Y985 and Y1077 motifs as SOCS3 recruitment sites in the murine leptin receptor. FEBS Lett 486: 33-37.

31. Risseeuw MD, De Clercq DJ, Lievens S, Hillaert U, Sinnaeve D, et al. (2013) A "clickable" MTX reagent as a practical tool for profiling small-moleculeintracellular target interactions via MASPIT. ChemMedChem 8: 521-526.

32. De Bosscher K, Schmitz ML, Vanden Berghe W, Plaisance S, Fiers W, et al. (1997) Glucocorticoid-mediated repression of nuclear factor-kappaB-dependent transcription involves direct interference with transactivation. Proc Natl Acad Sci U S A 94: 13504-13509.

33. Bradford MM (1976) A rapid and sensitive method for the quantitation of microgram quantities of protein utilizing the principle of protein-dye binding. Anal Biochem 72: 248-254.

34. Helsens K, Colaert N, Barsnes H, Muth T, Flikka K, et al. (2010) ms_lims, a simple yet powerful open source laboratory information management system for MS-driven proteomics. Proteomics 10: 1261-1264.

35. De Bosscher K, Vanden Berghe W, Vermeulen L, Plaisance S, Boone E, et al. (2000) Glucocorticoids repress NF-kappaB-driven genes by disturbing the interaction of $\mathrm{p} 65$ with the basal transcription machinery, irrespective of coactivator levels in the cell. Proc Natl Acad Sci U S A 97: 3919-3924.

36. Beck IM, Vanden Berghe W, Vermeulen L, Bougarne N, Vander Cruyssen B, et al. (2008) Altered subcellular distribution of MSK1 induced by glucocorticoids contributes to NF-kappaB inhibition. EMBO J 27: 1682-1693.

37. Ran R, Lu A, Zhang L, Tang Y, Zhu H, et al. (2004) Hsp70 promotes TNFmediated apoptosis by binding IKK gamma and impairing NF-kappa B survival signaling. Genes Dev 18: 1466-1481.

38. Tang D, Kang R, Xiao W, Wang H, Calderwood SK, et al. (2007) The antiinflammatory effects of heat shock protein 72 involve inhibition of high-mobilitygroup box 1 release and proinflammatory function in macrophages. J Immunol 179: $1236-1244$.

39. Gossye V, Elewaut D, Bougarne N, Bracke D, Van Calenbergh S, et al. (2009) Differential mechanism of NF-kappaB inhibition by two glucocorticoid receptor modulators in rheumatoid arthritis synovial fibroblasts. Arthritis Rheum 60: 3241-3250.

40. van Loo G, Sze M, Bougarne N, Praet J, Mc Guire C, et al. (2010) Antiinflammatory properties of a plant-derived nonsteroidal, dissociated glucocorticoid receptor modulator in experimental autoimmune encephalomyelitis. Mol Endocrinol 24: 310-322.

41. Bachar-Dahan L, Goltzmann J, Yaniv A, Gazit A (2006) Engrailed-1 negatively regulates beta-catenin transcriptional activity by destabilizing beta-catenin via a glycogen synthase kinase-3beta-independent pathway. Mol Biol Cell 17: 2572 2580 .

42. Romero D, Iglesias M, Vary CP, Quintanilla M (2008) Functional blockade of Smad4 leads to a decrease in beta-catenin levels and signaling activity in human pancreatic carcinoma cells. Carcinogenesis 29: 1070-1076.

43. Song DH, Kaufman JC, Borodyansky L, Albanese C, Pestell RG, et al. (2005) Gastrin stabilises beta-catenin protein in mouse colorectal cancer cells. Br J Cancer 92: 1581-1587.

44. Lievens S, Peelman F, De Bosscher K, Lemmens I, Tavernier J (2011) MAPPIT: a protein interaction toolbox built on insights in cytokine receptor signaling. Cytokine Growth Factor Rev 22: 321-329.

45. Morimoto RI (1998) Regulation of the heat shock transcriptional response: cross talk between a family of heat shock factors, molecular chaperones, and negative regulators. Genes Dev 12: 3788-3796.

46. Feinstein DL, Galea E, Aquino DA, Li GC, Xu H, et al. (1996) Heat shock protein 70 suppresses astroglial-inducible nitric-oxide synthase expression by decreasing NFkappaB activation. J Biol Chem 271: 17724-17732.

47. Dunsmore KE, Denenberg AG, Page K, Wong HR (2006) Mechanism and function of heat shock-dependent IkappaBalpha expression. Inflamm Res 55: 254-259.

48. Wong HR, Ryan MA, Menendez IY, Wispe JR (1999) Heat shock activates the I-kappaBalpha promoter and increases I-kappaBalpha mRNA expression. Cell Stress Chaperones 4: 1-7.

49. Reuter KC, Loitsch SM, Dignass AU, Steinhilber D, Stein J (2012) Selective non-steroidal glucocorticoid receptor agonists attenuate inflammation but do not impair intestinal epithelial cell restitution in vitro. PLoS One 7: e29756.

50. Yemelyanov A, Czwornog J, Gera L, Joshi S, Chatterton RT, Jr., et al. (2008) Novel steroid receptor phyto-modulator compound a inhibits growth and survival of prostate cancer cells. Cancer Res 68: 4763-4773.

51. Hunter-Lavin C, Davies EL, Bacelar MM, Marshall MJ, Andrew SM, et al. (2004) Hsp70 release from peripheral blood mononuclear cells. Biochem Biophys Res Commun 324: 511-517.

52. Johnson JD, Fleshner M (2006) Releasing signals, secretory pathways, and immune function of endogenous extracellular heat shock protein 72 . J Leukoc Biol 79: 425-434. 
53. Mambula SS, Stevenson MA, Ogawa K, Calderwood SK (2007) Mechanisms for Hsp70 secretion: crossing membranes without a leader. Methods 43: 168175.

54. McDonough H, Patterson C (2003) CHIP: a link between the chaperone and proteasome systems. Cell Stress Chaperones 8: 303-308.

55. Oian SB, McDonough H, Boellmann F, Gyr DM, Patterson C (2006) CHIPmediated stress recovery by sequential ubiquitination of substrates and Hsp70. Nature 440: 551-555.

56. Bush KT, Goldberg AL, Nigam SK (1997) Proteasome inhibition leads to a heat-shock response, induction of endoplasmic reticulum chaperones, and thermotolerance. J Biol Chem 272: 9086-9092.

57. Kawazoe Y, Nakai A, Tanabe M, Nagata K (1998) Proteasome inhibition leads to the activation of all members of the heat-shock-factor family. Eur J Biochem 255: 356-362.

58. Mathew A, Mathur SK, Jolly C, Fox SG, Kim S, et al. (2001) Stress-specific activation and repression of heat shock factors 1 and 2. Mol Cell Biol 21: 71637171.

59. Stangl K, Gunther C, Frank T, Lorenz M, Meiners S, et al. (2002) Inhibition of the ubiquitin-proteasome pathway induces differential heat-shock protein response in cardiomyocytes and renders early cardiac protection. Biochem Biophys Res Commun 291: 542-549.
60. Kukreti H, Amuthavalli K, Harikumar A, Sathiyamoorthy S, Feng PZ, et al. (2013) Muscle-specific microRNAl (miRl) targets heat shock protein 70 (HSP70) during dexamethasone-mediated atrophy. J Biol Chem 288: 66636678 .

61. Lanz RB, McKenna NJ, Onate SA, Albrecht U, Wong J, et al. (1999) A steroid receptor coactivator, SRA, functions as an RNA and is present in an SRC-1 complex. Cell 97: 17-27.

62. Cooper C, Vincett D, Yan Y, Hamedani MK, Myal Y, et al. (2011) Steroid Receptor RNA Activator bi-faceted genetic system: Heads or Tails? Biochimie 93: 1973-1980.

63. Colley SM, Leedman PJ (2011) Steroid Receptor RNA Activator-A nuclear receptor coregulator with multiple partners: Insights and challenges. Biochimie 93: 1966-1972.

64. Wadekar SA, Li D, Periyasamy S, Sanchez ER (2001) Inhibition of heat shock transcription factor by GR. Mol Endocrinol 15: 1396-1410.

65. Wadekar SA, Li D, Sanchez ER (2004) Agonist-activated glucocorticoid receptor inhibits binding of heat shock factor 1 to the heat shock protein 70 promoter in vivo. Mol Endocrinol 18: 500-508.

66. Belguise K, Kersual N, Galtier F, Chalbos D (2005) FRA-1 expression level regulates proliferation and invasiveness of breast cancer cells. Oncogene 24: $1434-1444$. 